\title{
COMPARATIVE EVALUATION OF THE IMPACTS OF DOMESTIC GAS AND ELECTRIC HEAT PUMP HEATING ON AIR POLLUTION IN CALIFORNIA
}

Final Report

Prepared for the

California Institute for Energy Efficiency

\author{
by \\ Ahmad Ganji \\ Division of Engineering \\ San Francisco State University \\ San Francisco, CA
}

July 1992

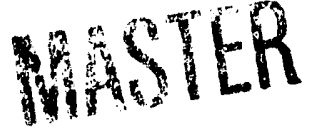




\section{ABSTRACT}

Residential space and water heating accounts for approximately $12 \%$ of California's and 15\% of the United States' energy consumption. Most of the residential heating is by direct use of natural gas. Combustion of natural gas is a contributor to the overall air pollution, especially $C O$ and NOx in the urban areas. Another efficient method for domestic water and space heating is use of electric heat pumps, the most popular category of which uses air as its heat source. Electric heat pumps do not emit air pollutants at the point of use, but use electric power, which is a major contributor to air pollution at its point of generation from fossil fuels. It is the siecific objective of this report to evaluate and compare the energy efficiency and source air pollutants of natural gas heaters and electric heat pumps used for domestic heating. Effect of replacing natural gas heaters with electric heat pumps on air pollutant emissions due to domestic heating in two urban areas and in California as a whole has also been evaluated. The analysis shows that with the present state of technology, electric heat pumps have higher heating efficiencies than natural gas heaters. Considering the current electricity generation mix in the U.S., electric heat pumps produce two to four times more Nox, much less $\mathrm{CO}$, and comparable amount of $\mathrm{CO}_{2}$ per unit of useful heating energy compared to natural gas heaters. With California mix, electric heat pumps produce comparable Nox and much less $c o$ and approximately $30 \%$ less $\mathrm{CO}_{2}$ per unit heat output. Replacement of natural gas heaters with electric heat pumps will slightly increase the overall NOx, and reduce $\mathrm{CO}$ and $\mathrm{CO}_{2}$ emissions in California. The effect of advanced technology power generation and heat pump heating has also been analyzed. 


\section{ACRTORTEDGEMANT}

The research reported here has been funded by the California Institute for Energy Efficiency (CIEE), a research unit of the University of California. Publication of research results does not imply CIEE endorsement of or agreement with these findings, nor that any of CIEE sponsors. The author is grateful to CIEE and the project manager Dr. Edward vine for their kind support in the course of this work. The author would also like to thank Mr. Bryce Lloyd who significantly contributed to the calculation and plotting the results. The comments of the reviewers of the draft manuscript enhanced the quality of this report and are sincerely appreciated. 
ABSTRACT. . . . . . . . . . . . . . . . . . i

ACKNOWLEDGEMENT . . . . . . . . . . . . . . . $i i$

TABLE OE CONTENTS . . . . . . . . . . . . . . . i ii

GLOSSARY AND NOMENCLATURE . . . . . . . . . . . . iv

1 - INTRODUCTION. . . . . . . . . . . . . . . . . . 1

2 - HEAT PUMPS AND ELECTRICITY GENERATION

TECHNOLOGIES. . . . . . . . . . . . . . . . 5

2.1 - Heat Pumps Technology . . . . . . . . . . 5

2.2 - Advanced Electricity Generation

Technologies. . . . . . . . . . . . 7

3 - EEFICIENCY AND EMISSIONS DATA

AND STANDARDS . . . . . . . . . . . . . . 10

3.1 - Efficiency Data . . . . . . . . . . 10

3.2 - Emission Data . . . . . . . . . . . . 12

4 - ENERGY EFEICIENCY COMPARISON OF

HEAT PUMPS AND GAS HEATERS. . . . . . . . . . . . . 16

5 - AIR POLLUTANT EMISSIONS OF HEAT PUMPS

AND GAS HEATERS . . . . . . . . . . . . . . . 20

6 - EFFECT OF REPLACEMENT OF DOMESTIC

GAS HEATERS WITH HEAT PUMPS

ON THE AIR POLLUTION IN CALIFORNIA. . . . . . . . . 33

7 - DISCUSSION, CONCLUSIONS AND

RECOMMENDATIONS . . . . . . . . . . . . . 52

8 - REFERENCES. . . . . . . . . . . . . . 57

APPENDIX A. . . . . . . . . . . . . . 61 


$\begin{array}{ll}\text { AFUE } & \text { Annual fuel utilization efficiency } \\ \text { COP } & \text { Coefficient of performance } \\ \text { EF } & \text { Energy efficiency } \\ \text { EI } & \text { Emission index } \\ \text { EM } & \text { Emission factor } \\ \text { ETHA } & \text { efficiency } \\ \text { E } & \text { Fractional share of a specific fossil fuel in the } \\ & \text { generation mix } \\ \text { g } & \text { Gram } \\ \text { HP } & \text { Heat pump } \\ \text { HSP } & \text { Heat rate } \\ \text { HV } & \text { Heating seasonal performance factor } \\ \text { Iit } & \text { Heating value } \\ \text { mg } & \text { Liter } \\ \text { N.G. (NG) } & \text { Nilli-gram } \\ \text { SCm } & \text { Standard cubic meter }\end{array}$




\section{1 - INTRODUCTION}

Residential space and water heating counts approximately for 128 of California's and 158 of the United States' national energy consumption. Three of the prevalent modes of heating are natural gas, electric resistance and heat pump heating.

Concerns over the cost and eventual depletion of non-renewable sources of energy, air pollutant emissions such as NOx and global warming $\mathrm{CO}_{2}$ has introduced new dimensions in the choice of the end use equipment such as those used for residential heating. In addition to the cost, overall end use energy efficiency and environmental consequences are expected to play an important role in the promotion and application of end use equipment.

Natural gas heaters (for both space and water heating) are among the oldest heating technologies in the modern world. They are simple, low cost, and easy to operate and maintain. If maintained properly, they emit insignificant amounts of carbon monoxide (CO) and volatile organic compounds (VOC), and their emissions are restricted to NOx and $\mathrm{CO}_{2}$. Advanced gas burners have been developed which have NOx emissions as low as 10 to 15 ppm (Pam and Kesselring 1984) which are far below the current standard of South Coast Air Quality Management District (SCAQMD) for these gas heaters. Energy efficiencies in excess of $95 \%$ have been reported for some gas heaters. Relevant data and references will be presented in section 3 of this report.

Electric heat pumps have demonstrated progressive potential in terms of off-setting the generation and transmission losses of electricity, and have energy efficiencies which are comparable or even superior to the most advanced direct natural gas heating equipment. Energy efficiency and source pollutant emissions of 
electric heat pumps depend on electric generation heat rate and pollutant emissions, transmission and distribution efficiencies, and heat pump coefficient of performance (COP). COP is a nondimensional factor defined as the heat output divided by the electric energy input to the heat pump. It should be noted that COP of heat pumps is climate and thermostat setting dependent, and an equivalent standard heating seasonal performance factor (HSPF) in terms of Btu/KWH is used instead. This is essentially a standardized COP which includes the effect of cycling, frosting and supplemental heat. An electric resistance heatex can be considered as an electric heat pump with a COP of one.

Almost all electric heat pumps which are presently in use work on the basis of vapor compression cycle. Gas absorption cycle heat pump has been developed and even commercialized. But its market has been diminishing, although renewed efforts for its commercial development have recently gained some ground, mostly in Japan. While for most available systems, the heat source/sink is air, water source, ground coupling and solar assisted heat pumps have been developed and are used. Another technology which is being developed for both heating and cooling is natural gas engine heat pump. In most natural gas engine driven heat pump systems, recovered heat from the exhaust and engine coolant supplements the heating capacity of the heat pump cycle and adds to the heating efficiency of the system.

Direct heating by gas, use of electric heat pumps or gas engine heat pumps are three distinct paths for domestic space and water heating. The energy flow diagrams for these three paths are shown in Fig. 1.

The specific objectives of the research project reported here has been: 
1 - To perform a comparative evaluation of the overall energy efficiency and energy source pollutants of gas and electric heat pumps, and

2 - Evaluate the impact of electric heat pumps on air pollution in California.

Evaluation of the energy efficiency and pollutant emissions of gas engine heat pumps was not a part of this project. Some preliminary results of such an evaluation have been reported by Ganji (1991).

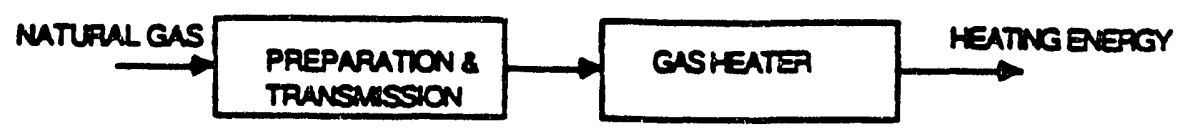

a- Natural gas heating path

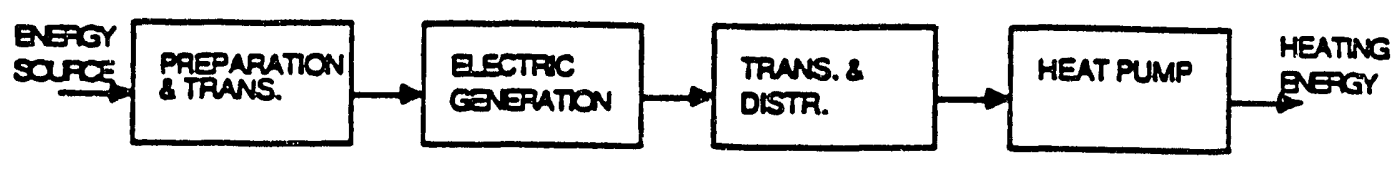

b. Electric heat pump heating path

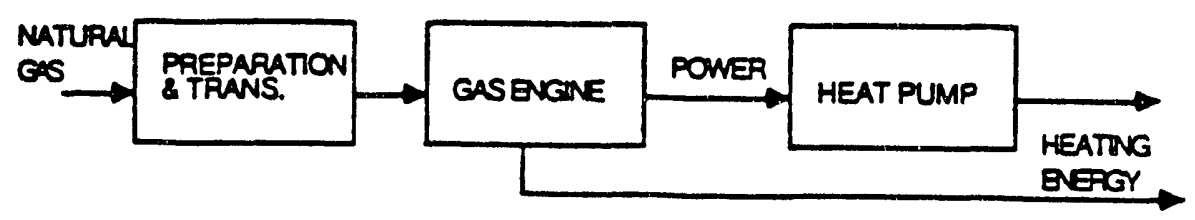

c. Gas engine heat pump heating path

Fig. 1 - Energy flow diagram for heating equipment using natural gas and electricity 
In section 2 the state of technology of heat pumps and electricity generation systems is briefly reviewed. Emission and efficiency data, and standards for gas heaters and fossil fuel power plants are presented in Section 3. In Sections 4 and 5 energy efficiency and energy source pollution of gas heaters and heat pumps are evaluated and compared. In Section 6 the impact of replacing gas heaters with electric heat pumps on air pollutant emissions in California is evaluated. The final conclusions and relevant recommendations of this research project are presented in section 7 . 


\section{2 - mEAT PURS AND ELECTRICITY GENERATION TECBNOLOGIES}

As will be described in the coming sections, the energy efficiency and energy source pollution of an electric heat pump directly depend on the coefficient of performance of the heat pump cycle and the thermal efficiency of electricity generation. This section presents a brief overview of the current heat pump and power generation technologies.

\section{1 - Beat Pumps Technology}

Currently heat pumps only perform at a fraction of their theoretical energy efficiency potential set by the second Law of Thermodynamics. The limit on the cop of heat pumps is determined by the Carnot Cycle concept. There is renewed and continuous research and development effort to enhance the performance, and to overcome the technical problems of heat pumps. Prcceedings of the International Energy Agency (IEA) Heat Pump conferences, Intersocietal Energy Conversion Engineering Conference (IECEC): EPRI and GRI publications are rich sources of information on the subject.

Heat pumps are categorized according to their thermodynamic cycles and their source and sink heating and cooling medium. Heat pump technology has been developed based on two distinct thermodynamic cycles. These are vapor compression and vapor absorption cycles. Wood (1982) presents detail description of these cycles. A wide variety of other cycles for general or special applications have also been developed or are under development. They include Brayton, Sterling, thermomagnetic, etc. (Chen et al. 1988).

Vapor compression cycle heat pumps using a variety of refrigerants has dominated the field and is expected to grow. It is simple, and adaptable to various applications for both heating and cooling. Efforts to improve the performance of vapor compression cycle heat 
pumps have focussed on developing improved refrigerants, especially of non-azeotropic type, variable speed drive compressors, microprocessor control systems, and better heat transfer surfaces (IEA 1982; Nelson 1989). Currently air source heat pumps with COP of over 2 (low temperature rating) to over 3 (high temperature rating) and water source heat pumps with COP over 4 are being marketed in the U.S. Ganji and Wheeler (1989) have reviewed the technology and advances in the field of heat pump water heaters. Their findings also apply to space heating heat pumps. Another recent development in the area of vapor compression cycle heat pumps is natural gas engine driven heat pumps. In these systems, essentially a natural gas fueled engine replaces the electric motor drive. In the heating mode, usually a heat recovery heat exchanger augments the heating capability of the heat pump cycle which improves the heating COP of the system. Development of gas engine driven heat pumps for domestic application in the United states is currently sponsored by the Gas Research Institute (GRI). Some details on the project have been presented by swain et al. (1986); Erench et al. (1989) and Harnish (1991).

Absorption heat pumps for application in the residential market have been reviewed by Phillips (1985). He concludes that the gas firing COP of advanced gas heat pumps can go up to 1.6 for heating and to 0.7 for cooling. The quoted COP is based on heating source energy. Other investigations into gas absorption cycles show that a cooling COP of 1 . is also attainable (Ohuchi 1985; McLinden and Klein 1985). The absorption cycles are simple, and highly efficient in the heating mode. But because of low cooling efficiency, flow reversal problem between heating and cooling modes and also the need for a high temperature source (usually natural gas), they have not been widely accepted in the residential market.

To improve the heating and cooling performance of heat pumps, a combination of vapor compression and gas absorption cycles are also under development. These are called combined compression - 
absorption cycles and have the potential for increased energy efficiency in the future (Ahlby and Hodgeff 1990). Except for the vapor compression cycle heat pumps, other heat pump technologies have enjoyed very marginal penetration into the California market and also U.S. as a whole. Consequently, only electro-motor driven vapor compression heat pumps have been considered in this investigation.

The source and/or sink in most heat pumps is air, however, ground source, water source, and solar assisted heat pumps have been developed and are currently being marketed in the United states, (EPRI 1990). Ganji and Wheeler (1989) have reviewed the technology of heat pump water heaters and present detailed discussion on various heat sources/sinks used in heat pumps.

\section{2 - Advanced Electricity Generation Tochnologies}

Performance of electric power plants is continuously improving due to the advancement of technology in several fronts. Cogeneration of electric power and process heat, advanced material for boilers and turbines, and a variety of combined cycles are the technologies that are emerging as efficient and environmentally sound alternatives to currently dominant electricity generation techniques.

Cogeneration systems are among the most efficient technologies for conversion of fossil fuels into a combination of electric power and process heat. Cogeneration systems greatly improve the utilization efficiency of fuels because they utilize the otherwise wasted heat which is a by-product of power production. Cogeneration systems are being developed for wide ranges of power and process heat production. Present and future cogeneration technologies have been reviewed by Dickenson et al. (1990). Cogeneration of electricity and process heat greatly reduces the amount of pollutants per unit product. The reduction can be up to $50 \%$ 
depending on the technology, the overall efficiency and the power efficiency of the system. Because of the small share of cogeneration in the current mixes of electricity generation in the U.S. (about 18, EIA 1990) and California (about 68, CEC 1989), its effect on the air pollutant emissions of heat pumps will not be considered here. Effect of high efficiency electricity generation is discussed in Section 4.

Improving turbine inlet temperature is another area of research and development for improving the efficiency of electricity generation from fossil fuels. This applies to both gas and steam turbines. Thermodyramic analysis of power generation cycles shows that improving the turbine ialet temperature directly improves the thermal efficiency of the cycle. The gas turbine establishment is moving in the direction of extensive use of aeroderivative gas turbine systems with substantially higher turbine inlet temperature for power production (Dickenson et al. 1990). Some of the latest General Electric aeroderivative gas turbines have a turbine inlet temperature of $2,500 \mathrm{~F}$ compared to $2,000 \mathrm{~F}$ for industrial heavy duty units. Introduction of new blade materials, and turbine cooling technologies is a continuous effort in the gas turbine industry. The potential for a quantum increase in steam turbine inlet temperature level (currently at about $1100 \mathrm{~F}$ ), and trial applications in smaller cogeneration type steam cycles has been discussed by Duffy et al. (1987). According to Duffy, with the current state of material technology, it has been proposed to use steam turbine inlet temperatures of up to $1,500 \mathrm{~F}$. Such an improvement (or even smaller magnitudes) in the inlet temperature of steam turbines will significantly improve the thermal efficiency of steam power cycles. The above report includes some detail information on the design of such systems.

Combined cycle power plants using a variety of fuels, and fluidized bed combustion for burning coal, are efficient low polluting technologies (compared to conventional fossil fuel burning power 
plants) which are being used and further developed. The state of the art in research, development and commercial application of these systems in the developing countries is introduced in EPRI (1989). According to Diehl (1989), combined cycle power plants using fluidized bed combustion technology are expected to have efficiencies in excess of 508. A recent advertisement by siemens claims achievement of $52.5 \%$ efficiency in a combined cycle power plant (Power Engineering, October 1991). Rao et al. (1991) have reported the results of their study on a new cycle called "Humid Air Turbine Cyclen and compared it with some combined cycle concepts. They claim that their concept can achieve better thermal efficiency and have higher environmental qualities compared to conventional combined cycles.

In conclusion, work on new concepts of power cycles based on realistic technological evaluations is assuring that power plants with thermal efficiencies in the 408 - 508 range $(8,500-6,800$ Btu/KWH heat rate) and above will be available and widespread in the near future. 


\section{3 - ERTICIENCY AND EMISSIONS DATA AND STANDARDS}

In studying and comparative evaluation of the efficiency and air pollutant emissions of various energy equipment, reliable data are vital to the accuracy and reasonableness of the results. Such data are often equipment and site dependent. Proper maintenance and operation of these equipment can significantly affect their air pollutant emission levels (EPA 1985) as well. In this report, whenever appropriate, we have used emission standards in our evaluations to avoid relying on equipment specific measurement data. If standards were not available (such as $c 0$ emissions standard for power plants,) an average measurement value has been used. All data are identified by the source.

\section{1 - Efficiency Data}

Table 1 presents the energy efficiency of gas water heaters, space heaters, and heat pumps. The data for some advanced pulse combustion gas heaters are also presented. The data presented by the Gas Appliance Manufacturers' Association (GAMA) are commercial ratings of these equipment. Data presented here do not include the electricity consumption by the fan in the forced air heaters. We did a survey on the effect of fan energy consumption on the efficiency of forced air furnaces produced by one of the large manufacturers of these products. On average, in the case of forced air heaters, the fan electric consumption will result in approximately 1.58 reduction in the reported efficiency. Natural gas water heaters usually do not use any auxiliary electrical equipment.

Energy efficiency of fossil fuel electric power plants depends on the energy source (coal, natural gas, oil, etc), and more importantly on the technology of the plant. In section 2 the efficiency data for some advanced plants was presented. An average efficiency of $33 \%$ (EIA 1990) have been reported for the U.S. 
Overall average efficiency of generation of power from thermal sources in California has also been reported to be the same (CEC 1990c).

Electric utility industry usually uses heat rate (HR), which is a cost/benefit factor instead of energy efficiency. HR is the inverse of energy efficiency and is usually quoted in terms of Btu/KWH referring to the fuel energy input divided by electric energy output.

Table 1. Representative values for the energy efficiency of gas heaters and COP of electric heat pump heaters.

TYRE

EFICIENCY (8) SOORCE

\section{Gas hoaters}

Forced air furnaces

58. -97.

GAMA (1988)

Water heaters

$40 . \quad-72$.

GAMA (1988)

Pulse combustion

90 .

Thrasher (1986)

water heater

Pulse combustion

42. -78 .

Soedel et al.(1984)

water heaters

Pulse combustion

90.

Whitlock et al(1982)

space and water

heater

Pulse combustion

air heaters

91. - 94 Adams (1982)

Elect. hoat pumps COP

Water heater

$2.80-3.50$

GAMA (1988)

Space heater

$1.80-3.20$

ARI (1991) 


\section{2 - Emissions Data}

Major pollutants from gas heaters and natural gas fueled power plants are NOx, $C O$ and VOC. The amount of particulate matter produced from natural gas combustion is negligible. Stringent Nox regulation, especially in southern California, has resulted in development of low Nox gas burners, which can be used in both space heaters and water heaters. Other pollutants from gas heaters are not regulated and measured data for them is scarce. Traynor et al. (1989) have summarized some of the available measurement data for these systems. Available data for water and forced air gas heaters is summarized in Table 2. All NOx measurements are on $\mathrm{NO}_{2}$ basis. NOx emission standard for California South Coast Air Quality Management District (SCAQMD) is also provided.

In the course of this study ten manufacturers of gas heaters were contacted for data on air pollutants from their equipment. It was promised that the name of the manufacturer will remain confidential in reporting the data. Three manufacturers responded, and two provided data (manufacturers $1 \& 2$ ), and the data for one of them was in detail. Their data is also presented in Table 2.

Air pollutant emissions from electric power plants depend mainly on the fuel and also on the technology of electricity generation. coal and oil fired plants emit sox and particulate (both of which are regulated by the federal and state governments) as well as co, VOC and NOx. CO and VOC emissions are not regulated. This is because the combustion technology used in utility boilers does not cause much $C O$ and VOC emissions, while there is also a strong economic incentive on the part of the electric utilities to keep these emissions as low as possible. On the other hand, Nox is regulated at the local and national levels. Data on $C O$ and voc from power plants are scarce. Table 3 includes some measured data as well as the standards for NOx, CO and VOC. 


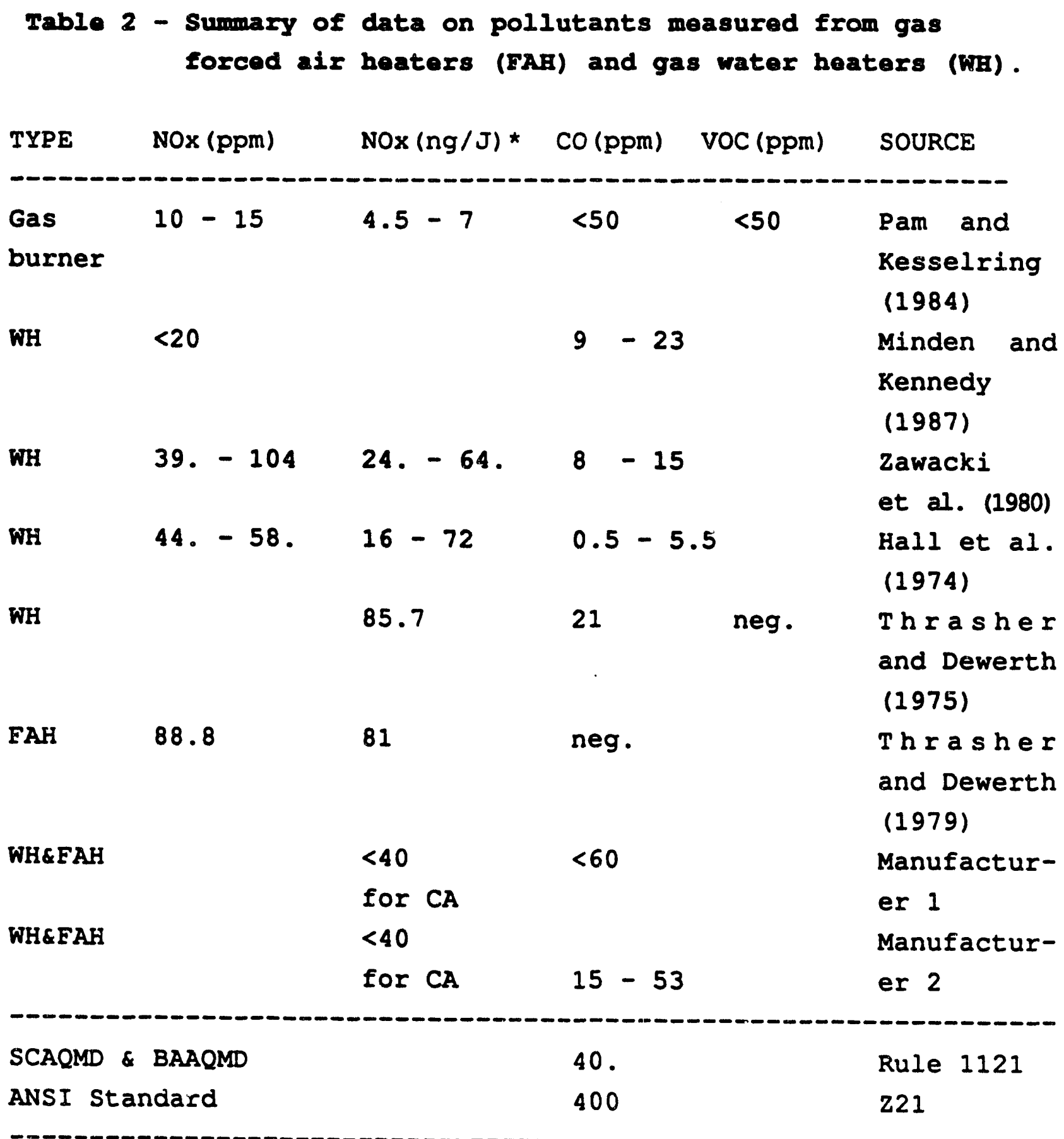

* Nox emissions per Joule heat output from the heater. This emission factor depends on the exhaust gas composition, heater efficiency and natural gas heating value. The data are reported without any modification. 
The emission data and standards for $\mathrm{SO}_{2}$ and particulate matter are not reported here, because the basic purpose of this work is to evaluate the pollutants from natural gas energy source, and natural gas combustion emits negligible amounts of these pollutants.

While NOx, CO, VOC and particulate matter from energy sources mostly depend on the combustion technology, $\mathrm{CO}_{2}$ emissions depend on the carbon content of the fuel.

Table 3 - Summary of measured ralues of pollutants and amission standards for electric power plants.*

TYPE HOx CO VOC SOURCE

Utility Boiler**

(mg/SCM NG)

(g/lit Oil)

(g/kg Coal)
8.8

8.0

5.0

Federal Standards

Gas and dist.

Oil

Residual Oil

Pulverized Coal SCAQMD stand.

for NG

SCAQMD Stand.

for liq. and

solid fuels
EPA (1985)

CER (1989a)

$86\left(\mathrm{ng} / J_{1 n}\right)$

$170\left(\mathrm{ng} / \mathrm{J}_{1 \mathrm{n}}\right)$

$300\left(\mathrm{ng} / J_{1 n}\right)$

125 (ppm)

Rule 474

225 (ppm)

Rule 474

For details of the limitations on the above values refer to the relevant reference.

* * These are typical measured values for power plants reported by EPA 
To calculate the $\mathrm{CO}_{2}$ emissions from typical fuels, we can assume complete combustion of all carbon content of the fuel to $\mathrm{CO}_{2}$, and then calculate the $\mathrm{CO}_{2}$ emissions per unit heat output of the heater.

Energy source emissions for electric heat pumps depend on the mix of electricity generation and generation technology. Operation of hydroelectric, nuclear and solar power stations does not generate any conventional air pollutants, while fossil fueled power stations are a major source of air pollution. Table 4 presents the most recent values of generation $\mathrm{mix}$ in the U.S. and California. Generation mix varies depending on the economics and availability of energy sources. Table 5 shows a history of generation mix in California in the period of 1982 to 1989 .

Table 4 - Mix of electricity generation in California and the $0 . s$. (8)

COAI MAT. GAS HOC. OII BYD. OTHER SOURCE

$\begin{array}{lcccccc}\text { California } & 10.7 & 34.1 & 22.5 & 5.6 & 27.1 & \text { CEC (1990a) } \\ \text { U.S. } & 55.8 & 9.5 & 19 . & 5.7 & 9.9 & \text { EIA (1990) }\end{array}$

Table 5 - Historic mix of electricity generation

in California (f) (CEC 1990b)

\begin{tabular}{|c|c|c|c|c|c|c|c|c|}
\hline YEAR & 1982 & 1983 & 1984 & 1985 & 1986 & 1987 & 1988 & 1989 \\
\hline Coal & 12.3 & 12.2 & 12.6 & 9.8 & 12.1 & 11.4 & 12.7 & 10.7 \\
\hline Natural Gas & 36.9 & 30.3 & 37.3 & 44.0 & 27.6 & 40.2 & 34.7 & 34.1 \\
\hline Nuclear & 2.8 & 4.8 & 9.4 & 13.2 & 19.3 & 21.5 & 23.4 & 22.5 \\
\hline Oil & 6.9 & 4.6 & 1.6 & 1.8 & 2.0 & 1.4 & 5.1 & 5.6 \\
\hline Hydro \& Others & 41.1 & 48.1 & 39.1 & 31.2 & 39.0 & 25.5 & 24.1 & 27.1 \\
\hline
\end{tabular}




\section{4 - ENERGY EFTICIENCY COMPARISON OF HEAT PONPS AND GAS BEATERS}

The main objective in this section is to compare the energy efficiency of gas heaters and heat pump heaters. To make this a meaningful comparison, we consider a common energy source, which is natural gas.

To have a common measure for evaluation of the efficiency of conversion of the source energy into useful heating energy, the energy efficiency (EF) of a heater is defined as:

\section{$E F$ = Heating energy delivered / Fuel energy input}

According to this definition, all energy that is used or wasted for delivering a given amount of heating energy is taken into consideration. This is equivalent to the annual fuel utilization efficiency (AFUE) as applied to gas heaters.

Energy efficiency of gas heaters and COP of heat pumps is presented in Table 1. Source energy efficiency of electric heat pumps depends on the COP of the heat pump itself, transmission efficiency of electric power from the generation source to the point of use, and finally the efficiency of conversion of the primary source of energy to electricity. Energy efficiency for an electric heat pump can be related to the above parameters through Eq. 1:

$$
E F=(C O P)_{H P} \cdot(E T H A)_{\text {erans }} /(H R)_{\text {gen. }} .
$$

Coefficient of performance of heat pumps depends on the technology of the system, as well as the climate of its operating environment. In order to standardize the COP, heating and cooling performance of electric heat pumps are measured according to specified DOE procedures. They are expressed in terms of heating seasonal performance factor (HSPF) and seasonal energy efficiency ratio (SEER) for cooling, both in KBtu/KWH. The COP used in this report 
can be considered as a standardized or seasonal factor. The HR term used in the above equation refers to power plant heat rate. In the following calculations, transmission and distribution efficiency (combined) of electricity (ETHA) from the source to the point of use has been assumed to be 908 which is a conservative estimate. U.S. average power transmission and distribution losses are reported to be $7 \%$ - $8.5 \%$ (EIA 1990) and for California it is about 88 (CEC 1990C).

Fig. 2 shows the energy efficiency (EF) of electric heat pumps as a function of the heat pump cycle COP and generation heat rate. For the sake of comparison, EF for an average (assumed to be 75\%) and best technology gas heater is also shown. 1992 Appliance Efficiency standards (CFR 1989b) mandates a $78 \%$ AFUE for gas furnaces, but there are a considerable number of older gas furnaces operating below the required efficiency (Table 1). The heat rates shown in the figure correspond to high efficiency $(8000 \mathrm{Btu} / \mathrm{KWH} \mathrm{HR}$ - 42.68 Efficiency), average efficiency (10000 Btu/KWH HR - 34\% Efficiency) and rather low efficiency (12000 Btu/KWH HR $-28.4 \%$ Efficiency) power production by fossil fuel power plants. This figure shows that a heat pump with an average $C O P$ of 3 , in combination with an average efficiency power plant and 908 transmission and distribution efficiency (which is a very conservative estimate) is competitive with the most efficient gas heater with an efficiency of 96\%. Compared to an average gas heater, an average heat pump approximately consumes $25 \%$ less source energy for the same amount of useful heat delivery. Improvements in generation heat rate and heat pump COP can significantly change the balance in favor of heat pumps. As an example, a heat pump with a COP of 5 , in combination with a power plant with a heat rate of $8000 \mathrm{Btu} / \mathrm{KWH}$ can be approximately twice as efficient as very high efficiency gas heaters. The above discussion holds for both water and space heating equipment. 
In the above discussion, it has been assumed that fossil fuels are the source energy. If we consider a case such as California where a significant portion of electricity is generated from non-fossil fuel energy sources (mostly hydro and nuclear), utilization of advanced technology heat pumps and power plants can result in a significant saving of non-renewable fuels such as natural gas. 


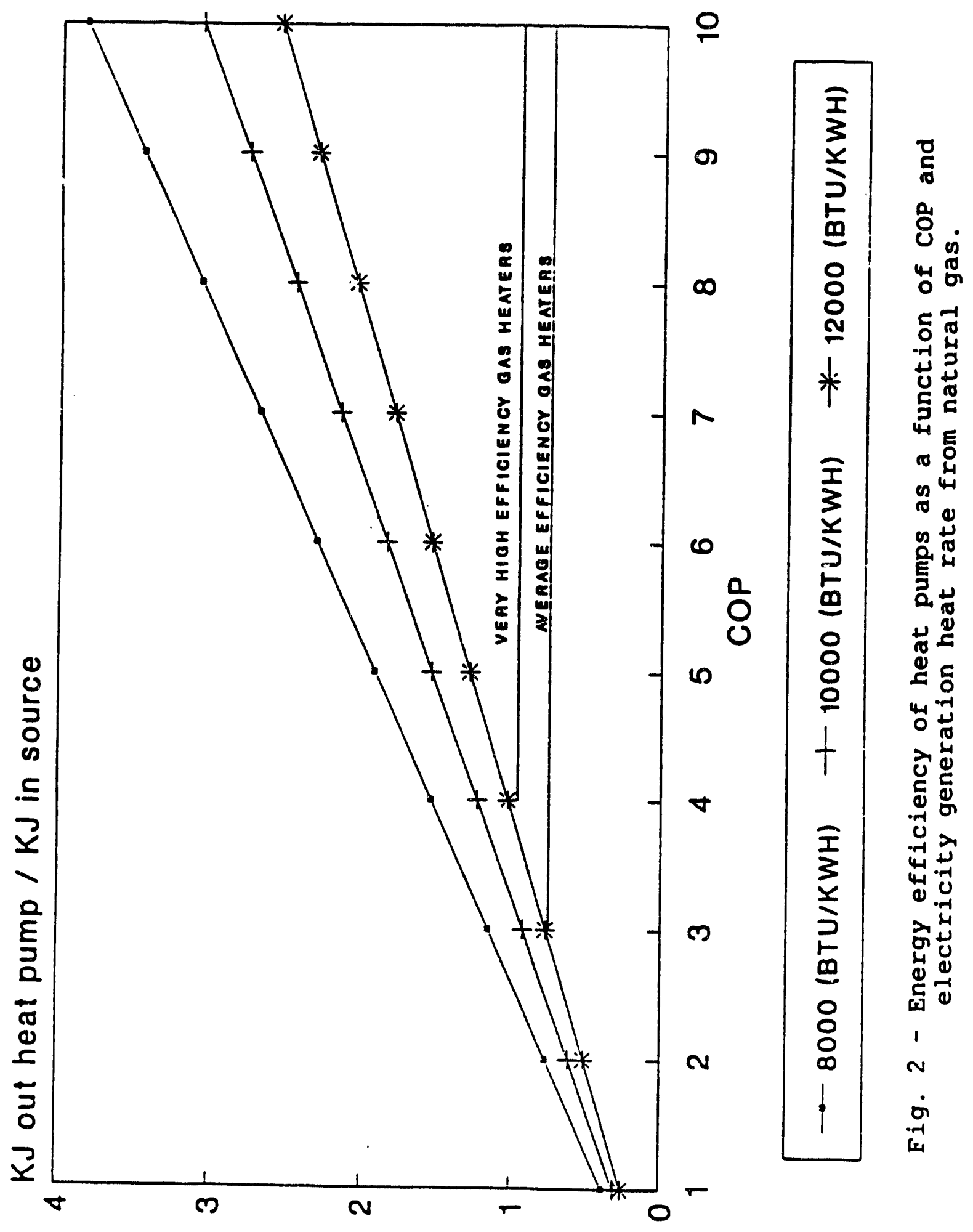




\section{5 - AIR POILUTANT BMISSIONS OF HEAT POMIPS AND GAS MEATERS}

To compare the effective air pollutant emissions from the domestic heaters under consideration, energy source emission factor (EM) has been defined as:

\section{EM = Pollutant produced / Heating energy delivered}

For air pollutants emitted from a gas heater, emission index is usually expressed in terms of parts per million (ppm) or pollutant produced per unit energy input. In either case the AFUE or source energy efficiency (EF) and the heating value of fuel influence the conversion of emission index to EM. Assumptions presented in Table 6 have been implemented in the calculations in this section.

Electric heat pumps do not emit any air pollutants at the point of use. Here it is assumed that there is no refrigerant leak into the air. Depending on the energy source, air pollutants may be emitted at the point of generation of electricity. Nuclear, hydro, solar, wind and some other energy sources do not emit any air pollutants when converted to electrical energy, while fossil fueled power plants are a major source of air pollution in the world. So the amount of air pollutants generated due to the use of electric power in a heat pump depend on the generation mix of electricity which drives the heat pump system. For electric heat pumps, the energy source emission factor will depend on the performance of the heat pump as well as the transmission and generation efficiencies as shown in the following relation:

$$
E M=(1 / C O P) \cdot\left(1 / E_{T H A} \text { trans }\right) \cdot(H R) \cdot(1 / H V) \cdot(E I)
$$

Eq. 2 holds for a single fuel such as coal or natural gas. If more than one type of fuel is used in the production of electricity, Eq. 2 becomes:

$$
E M=(1 / \mathrm{COP}) \cdot\left(1 / \mathrm{ETHA}_{\text {trans }}\right) \cdot \Sigma_{1}[\mathrm{~F} \cdot(\mathrm{HR}) \cdot(1 / \mathrm{HV}) \cdot(\mathrm{EI})]_{1}
$$


In Eq. 3 the summation applies to all fossil fuels. In the above equations, EI is the energy source emission index in terms of produced mass of pollutant per unit mass of fuel, and $E_{1}$ refers to the fraction of electricity produced from the specific fossil fuel. $F_{1}$ is actually the contribution of the specific type of fossil fuel in the generation mix.

\section{Table 6 - Major aseumptions for the calculations in this report}

Nox emission index from the fossil

fueled power plants

Co emission index from fossil

fueled power plants

NOx emission index from gas heaters

Co emission index from gas water heaters

Co emission index from gas forced air heaters

Average efficiency of gas heaters

Highe - heating value of natural gas

Heating value of coal

Average carbon content of coal

(mass basis)

Heating value of fuel oil

Average carbon content of carbon

in fuel oil (mass basis)
Table 3, standards of CFR (1989)

Table 3, Data from EPA (1985)

$40 \mathrm{ng} / \mathrm{J}$ output (SCAQMD Rule

1121)

$24.5 \mathrm{ng} / \mathrm{J}$ input (Traynor et al. 1989)

$11.4 \mathrm{ng} / \mathrm{J}$ input (Traynor et al. 1.989)

$75 \%$

$56000 \mathrm{KJ} / \mathrm{KG}$

$30000 \mathrm{KJ} / \mathrm{KG}$

808

$40,000 \mathrm{KJ} / \mathrm{KG}$

$86 \%$ 
Figures 3 through 5 show the emission factors for $\mathrm{NOx}, \mathrm{CO}$ and $\mathrm{CO}_{2}$ from electric heat pumps and natural gas heaters. The figures show tile effect of heat pump COP, and generation heat rate assuming that 1008 of the electricity is produced from natural gas. For an average heat rate of $10000 \mathrm{Btu} / \mathrm{KWH}$, the case of 50 \% natural gas in the generation mix has also been shown in these figures. In this case it has been assumed that the rest of the electric power is generated froin non-air polluting energy source(s). Federal Emission Standards (CFR 1989) and the data for gas burning utility boilers in (EPA 1985) have been respectively used to calculate the NOx and $C O$ emissions from electric power plants.

Fig. 3 shows that considering the Eederal standards for Nox emissions from power plants, an average heat pump ( $2<C O P<3)$ using electricity with an average generation heat rate of $10000 \mathrm{Btu} / \mathrm{KWH}$, will emit about twice as much NOx as regulated gas heaters in the South Coast and Bay Area Air Quality Management Districts in California. It also shows that in this case, even very advanced heat pumps in combination with high efficiency electricity generation from natural gas (HR $=8000 \mathrm{Btu} / \mathrm{KWH}$ ) can not compete with natural gas heaters.

Considering that more stringent regulations are being imposed on the level of allowable NOx emissions from electric generating equipment in California (see, for example SCAQMD Rule 1135), effective NOx emissions from the use of electric heat pumps will be lowered considerably. As an example, Rule 1135 of SCAQMD requires all electric power generating steam boiler systems operating in the district to lower their NOx emission level to $0.93 \mathrm{lb}$. NOx/MWH, effective December 1991. This is approximately less than one half of the Federal standards. If this limit is considered in the calculations presented here, an average electric heat pump will emit approximately the same amount of Nox compared to a regulated natural gas heater. This conclusion is based on Fig. 3 for the case of all natural gas based electricity generation. 
It should be emphasized here that NOx emission factor for gas heaters in these calculations is the NOx standard of South Coast Air Quality Management District (SCAQMD) standards. Actual emissions from gas heaters in California are expectad to be below this level. Detail data on Nox emissions supplied to us by one of the manufacturers show that for a wide variety of furnaces that they market in California, the NOx emissions are in the range of 21.9 to $38.9 \mathrm{ng} / \mathrm{J}$ output, with an arithmetic average of 31.4 for all different models. If we take this as a representative of the heaters marketed in California, it means that on average, Nox emissions from gas heaters will be approximately 208 below the SCAQMD standards shown in Fig. 3. If the emission standards for gas heaters are lowered, then even with new NOx standards for steam boilers, electric heat pumps will not be able to compete with natural gas heaters in this respect. On the other hand, as a marginal technology, ultra low Nox gas burners with Nox emissions less than $1 / 5$ of present SCAQMD standard are becoming available.

Fig. 4 and Table 2 show that gas heaters produce $c 0$ in a wide range, and that an average heat pump will emit less co than an average gas heater. If less than $50 \%$ of electricity consumed by a heat pump is produced from fossil sources, then the effective $c 0$ emissions from use of a heat pump will be approximately equivalent to the lowest level of $\mathrm{CO}$ emittance from natural gas heaters. Considering that $c o$ emissions in power plants is closely watched, and that there is no control on $\mathrm{CO}$ emissions from domestic gas burners, we may conclude that electric heat pumps effectively emit considerably less co than gas burners.

Fig. 5 represents $\mathrm{CO}_{2}$ production for domestic heating with natural gas as the energy source. It shows that the effective $\mathrm{CO}_{2}$ emissions from an average heat pump $(2<C O P<3)$ is equivalent to the $\mathrm{CO}_{2}$ emissions from advanced technology gas heaters. If less than 1008 of the electricity is produced from natural gas (a curve for $50 \%$ is shown), an average heat pump utilizing electricity from 
an average efficiency power plant is far superior to a natural gas heater from the standpoint of $\mathrm{CO}_{2}$ emissions.

Effect of electricity generation $\mathrm{mix}$ on $\mathrm{NOx}, \mathrm{CO}$ and $\mathrm{CO}_{2}$ emissions from heat pumps is presented in Figures 6 through 9. Fig. 6 examines the effect of all natural gas, all coal, and the U.S. and California mixes of electricity production on Nox emissions associated with heat pumps. The figure shows that with the U.S. mix, heat pumps have two to four times more energy source Nox emissions compared to natural gas heaters. For California mix, heat pumps at the present state of technology will have effective Nox emissions comparable to natural gas heaters. This conclusion is based on the fact that Nox emissions from power plants are kept below the Federal standards. Stringent NOx standards for steam power plants as a whole, and the fact that new SCAQMD rule requires the same emission levels for both natural gas and coal burning power plants, supports this conclusion. Lowering the NOx standard for gas heaters and/or introduction of ultra low Nox burners into the Californja market will change this balance in favor of gas heaters.

Fig. 7 shows the effect of generation mix on the emission factor of Co from heat pump heaters. It shows that coal combustion and other non-fossil energy sources will have a favorable reducing effect on the effective $C O$ emissions of heat pumps. Co emission data (Table 3 - EPA 1985) has been utilized for calculating co emission factor of heat pumps.

Fig. 8 shows that coal combustion generates approximately twice as much $\mathrm{CO}_{2}$ per unit energy output compared to natural gas. This is due to higher carbon content and lower heating value of coal compared to natural gas: Considering the U.S. mix of electricity generation, an average heat pump will produce approximately the same amount of $\mathrm{CO}_{2}$ per unit of useful heat compared to an average natural gas heater. With California mix, heat pumps will produce 
approximately $1 / 3$ less $\mathrm{CO}_{2}$ compared to natural gas heaters.

Fig. 9 demonstrates the effect of the total amount of fossil fuels (coal and natural gas) and the percentage of each on the $\mathrm{CO}_{2}$ emission factor of heat pumps. This figure can serve as an approximate chart for finding the effect of generation mix on the effective $\mathrm{CO}_{2}$ emissions from heat pumps. For the sake of simplicity, oil has not been included in the above graph. The horizontal axis represents the share of fossil fuels (considered as coal and natural gas) in the electricity generation. The percentage corresponding to each line represents the ratio of coal and natural gas in the share identified on the horizontal axis. For example, if the share of fossil fuels in the generation mix is 408, and half of the electricity generated from fossil fuels is coal based, then the intersection of the vertical line at 408 and 50 coal line will represent the $\mathrm{CO}_{2}$ emission factor of the heat pump to be approximately $32 \mathrm{mg} \mathrm{CO}_{2} / \mathrm{KJ}$ heat output. 


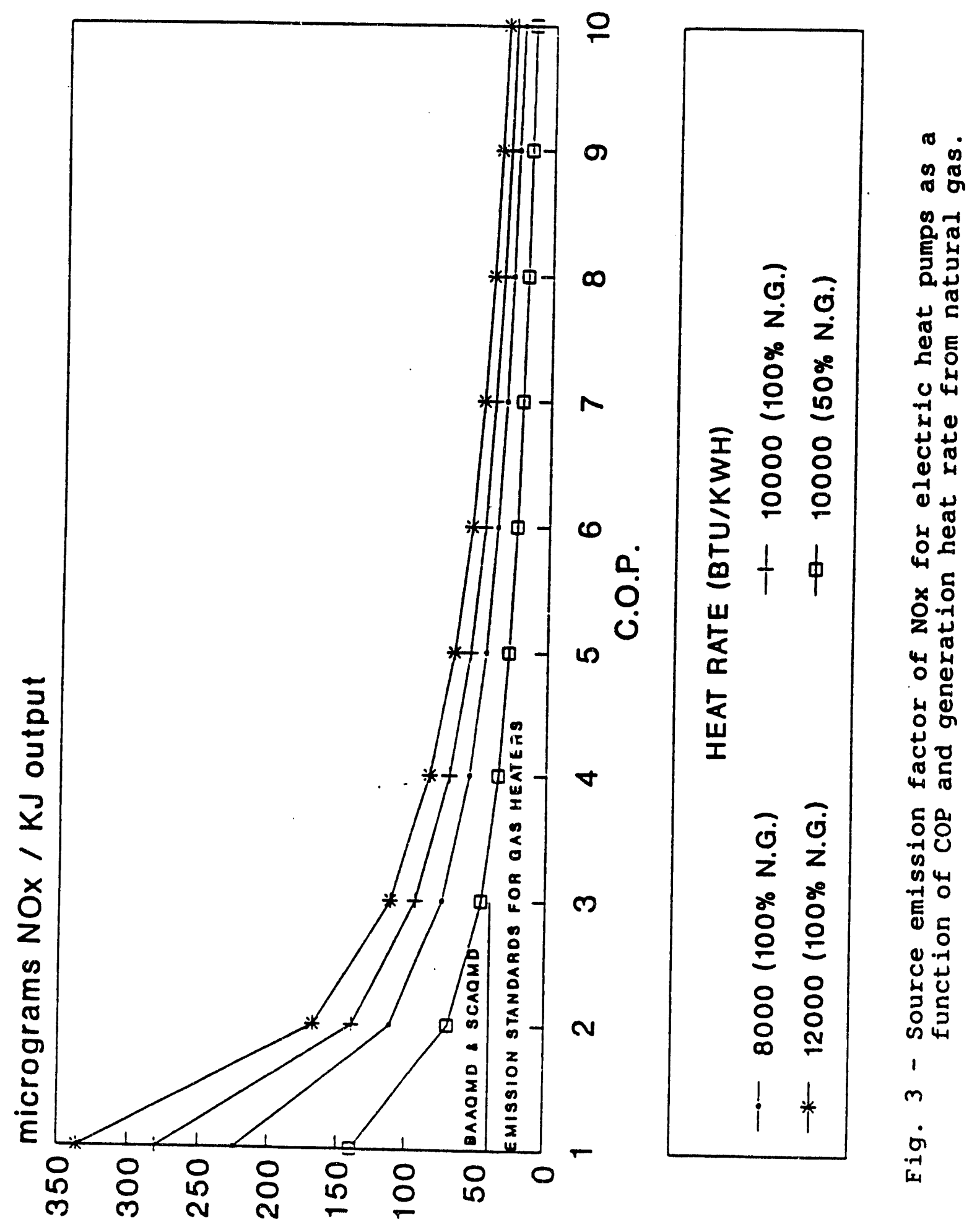




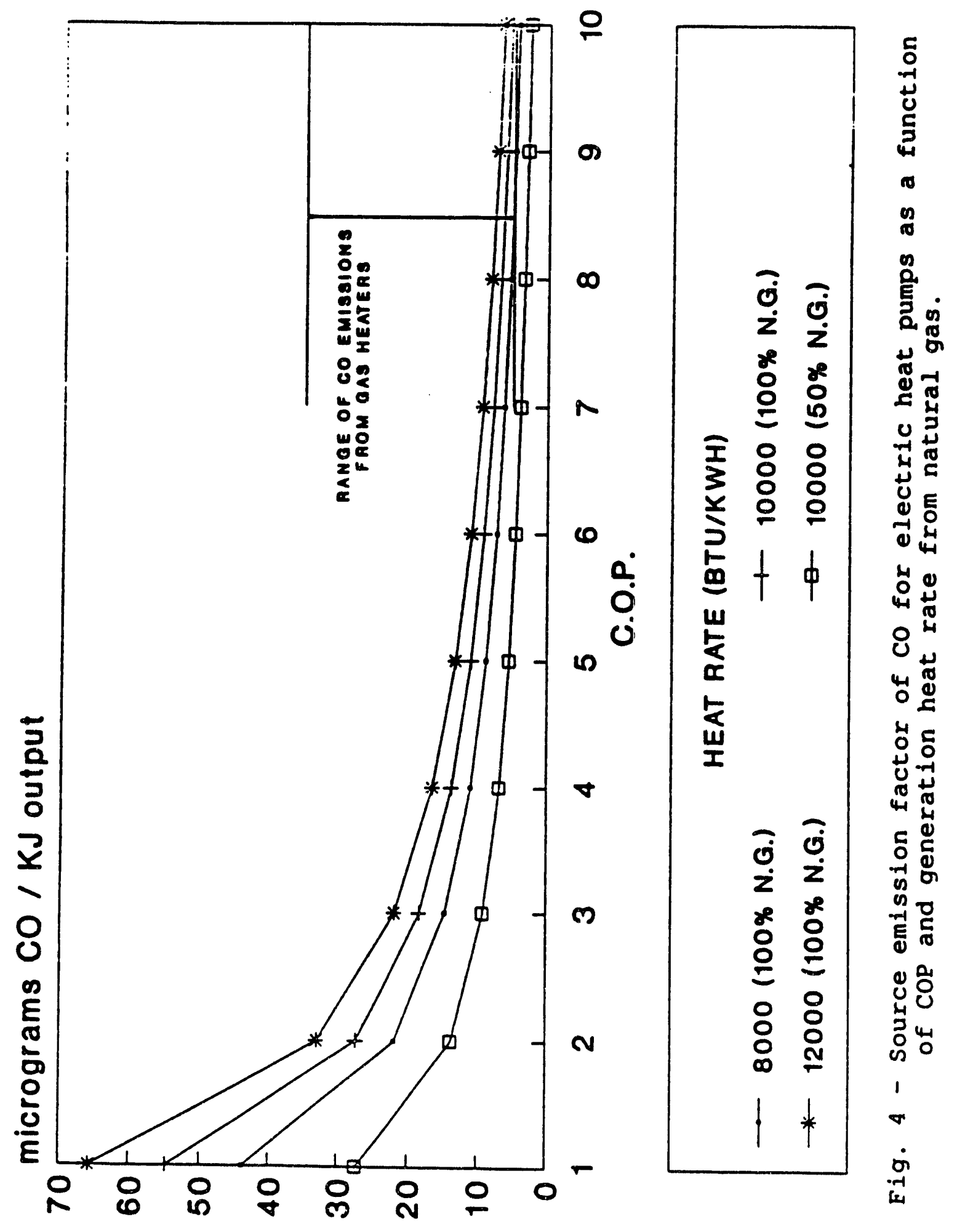




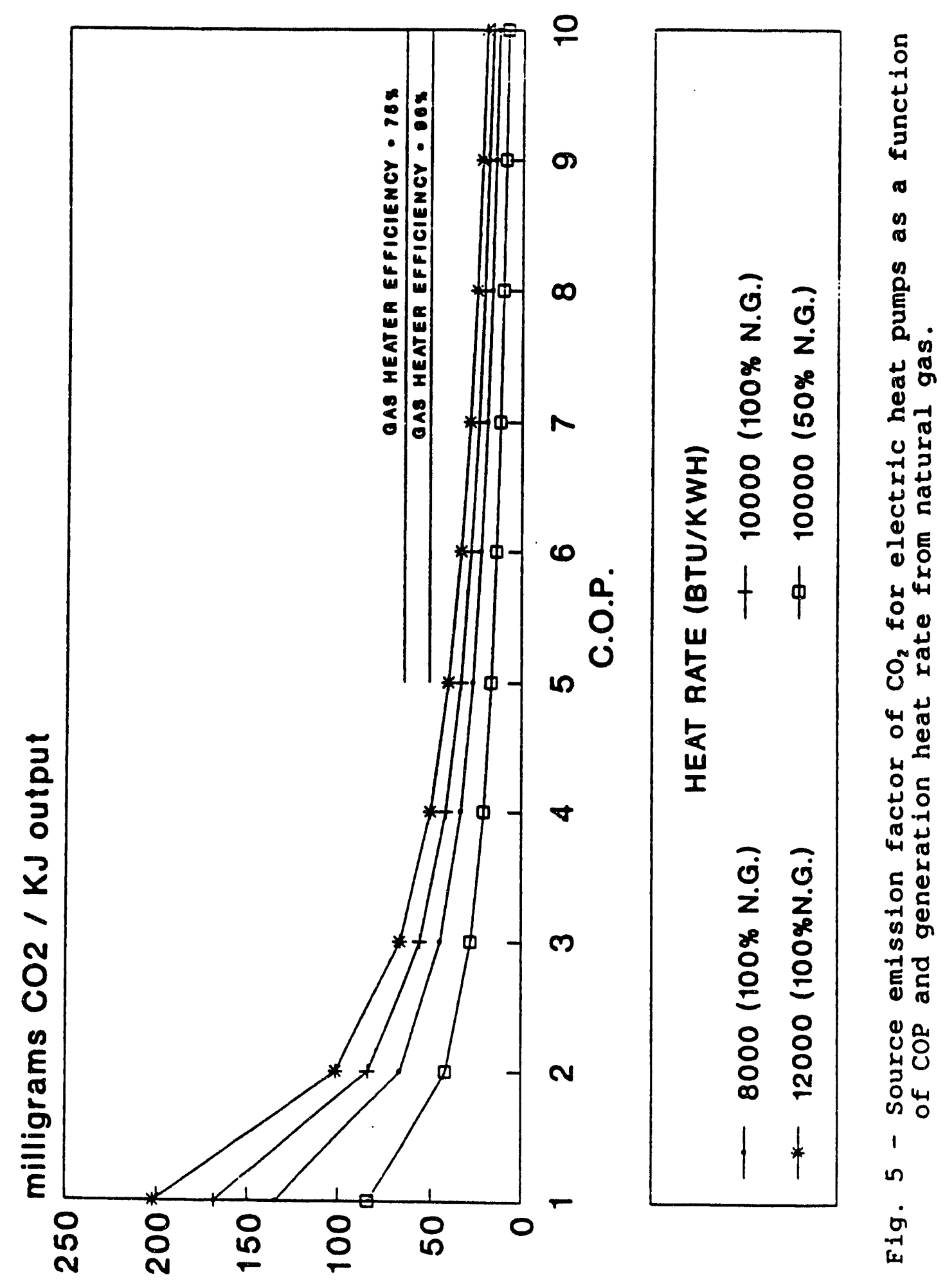




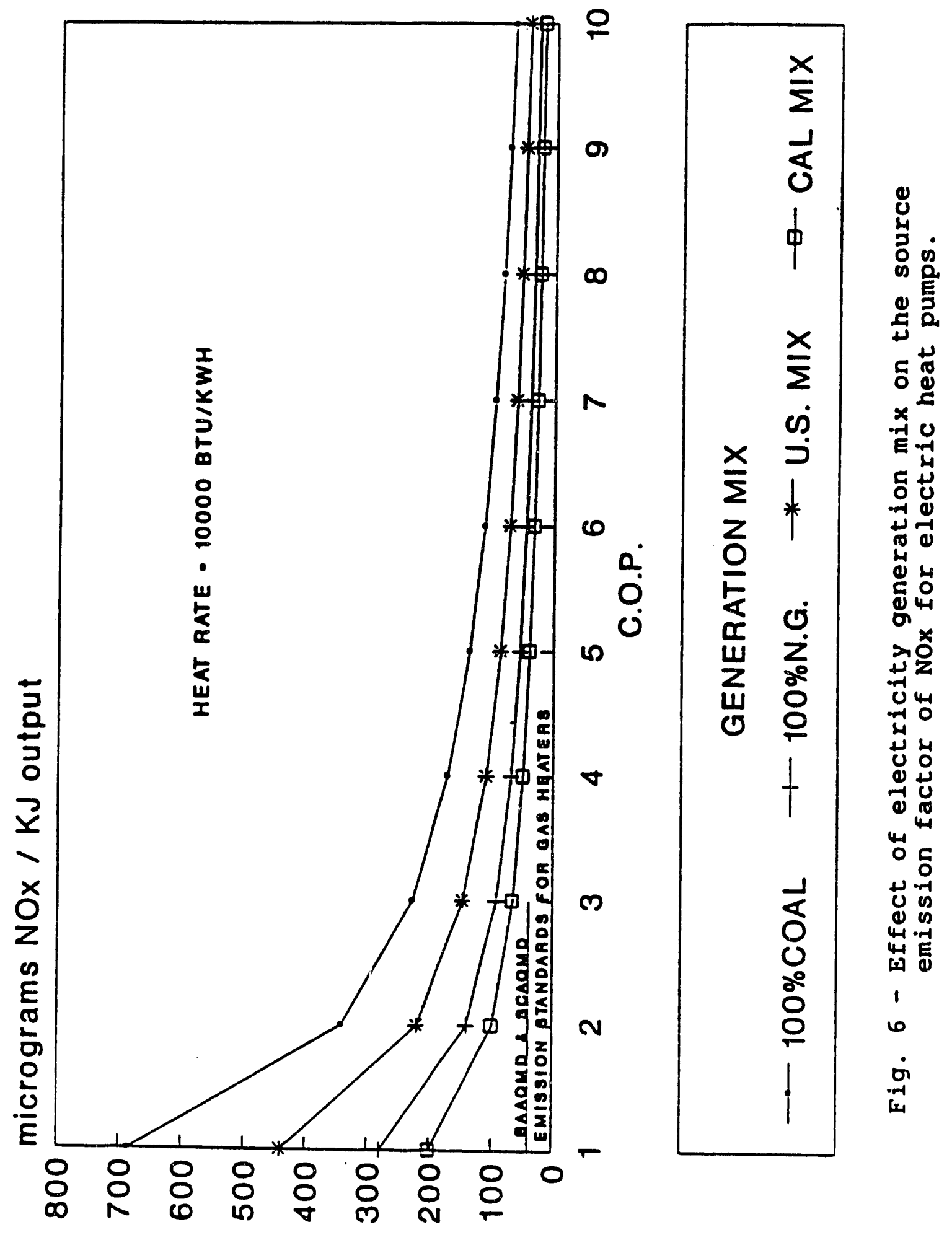




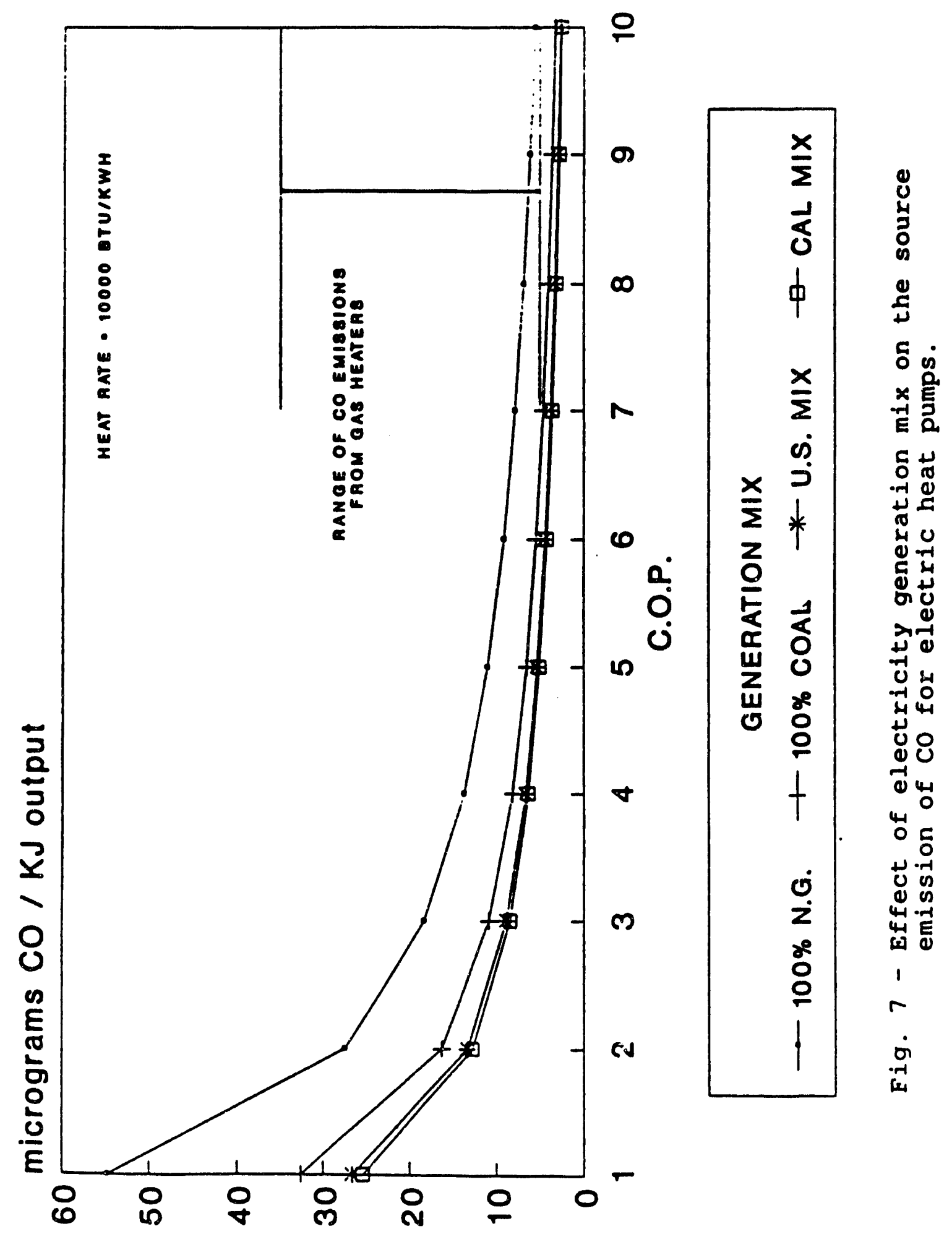




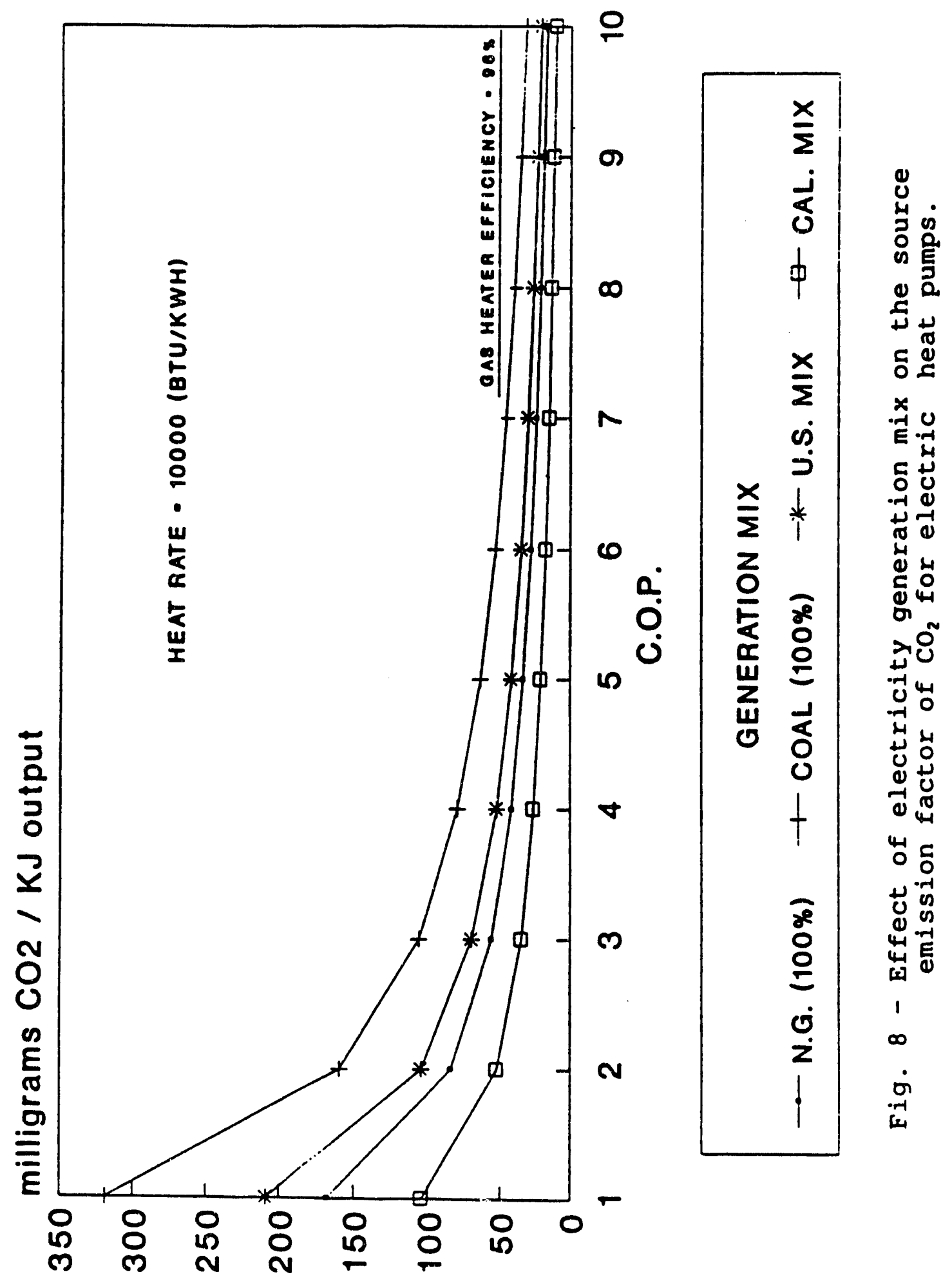




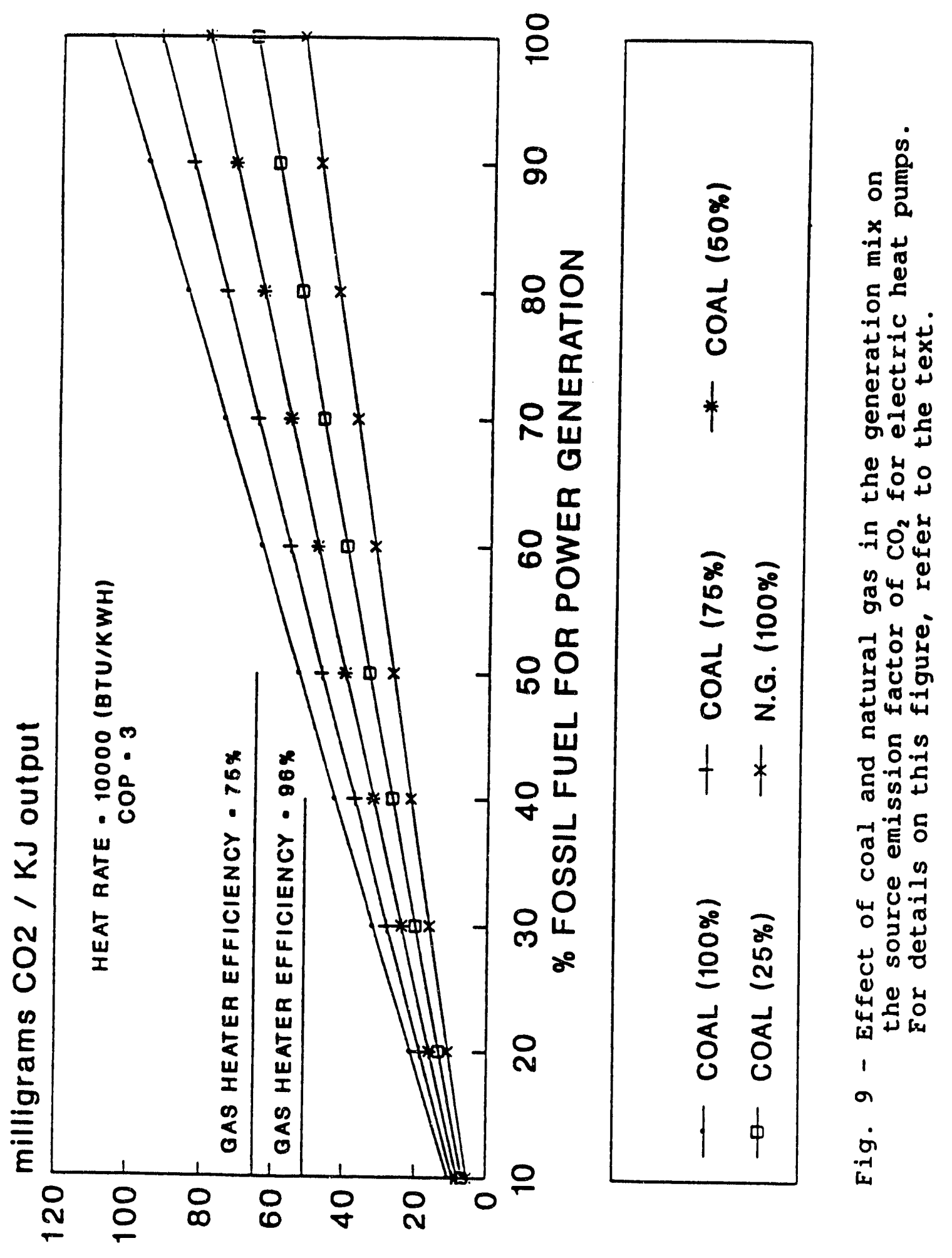


6 - EEEECT OF RHPIACEMANT OF DOMSTIC GAS HEATERS WITH EIECTRIC ERAT PONPS ON AIR POTLUTION IN CALITORNIA

In this section the effect of replacement of domestic gas heaters with heat pumps on the overall NOx, $\mathrm{CO}$ and $\mathrm{CO}_{2}$ pollutant emissions in two urban areas as well as California as a whole will be discussed. The selected regions are San Francisco Bay Area Air Basin and combined South Coast and San Diego Air Basins. The reason for this selection was the availability of detailed data from gas utilities for calculation of an approximate annual gas consumption for domestic heating in each region. For example, SDG\&E serves natural gas to parts of South Coast Air Basin and the data for those areas could not be separated from the San Diego Area. The methodology for calculation of the pollutants emitted by gas heaters is as follows:

1 - Annual natural gas consumption rate in each region is calculated based on the utilities' data on the total number of households, percent of households which use natural gas for heating, and the average annual gas consumption rate of a household.

2 - The amount of pollutant emissions for $\mathrm{NOx}, \mathrm{CO}$ and $\mathrm{CO}_{2}$ are calculated based on the assumptions provided in Table 6 .

3 - To calculate the effect of incremental conversion of gas heaters to heat pump heaters, emission factors corresponding to the COP under consideration and the California electricity generation mix extracted from the calculations of Section 5 were used. The 1990 value for California mix was also used for calculations in the Air Basins under consideration, although the local utility's generation mix might be somewhat different. This assumption will make the results more consistent for cross referencing although slight.ly less accurate. 
Number of households, percentage of households using natural gas for water and space heating, and average natural gas consumption rate by these appliances in the service areas of California gas utilities are shown in Table 7. Tables 8 and 9 show the annual natural gas consumption, NOx, $\mathrm{CO}$ and $\mathrm{CO}_{2}$ pollution due to natural gas heating in each gas utility service area, California as a whole (which closely approximates the sum of the values in the service areas shown), San Erancisco Bay Area Air Basin and combined South Coast and San Diego Air Basins. All data are for 1986 except the data from SDG\&E, which is for 1989. These are the years for which the data were available. No special attempt was made to correct the SDG\&E data for 1986. The emissions data calculated here will serve as a basis for comparison of the effective air pollutant and emissions of replacing gas heaters with heat pumps.

Effect of hypothetical replacement of natural gas heaters with heat pumps on the total NOx, $\mathrm{CO}$ and $\mathrm{CO}_{2}$ pollutant emissions due to domestic heating in California is shown in Figures 10,11 and 12 respectively. The data in the above figures have been produced for three values of COP of $2 ; 3$ and 4 , and two heat rates of 10,000 and $8,000 \mathrm{Btu} / \mathrm{KWH}$. COP of 4 and heat rate of $8,000 \mathrm{Btu} / \mathrm{KWH}$ represent advanced heat pump and electricity generation technologies respectively.

These figures show that as heat pump COP increases, the total amount of source pollutants will decrease. Replacement of domestic gas heaters with present technology heat pumps at any level will increase the total Nox emissions in California. The increase will be more substantial for heat pumps and power generation (fossil based) with poor performance. Advanced technology heat pumps with a COP of 4 will produce slightly more NOx when they replace the gas heaters at any level of conversion. This is in agreement with our conclusions in section 5. Fig. 11 shows that heat pumps will reduce the co emissions at any level of conversion. Heat pumps with higher $C O P$ and also power plants with lower heat rates will 
have favorable effects on the reduction of $c 0$ emissions due to domestic heating. Fig. 12 shows that replacement of gas heaters with heat pumps has a favorable effect on the reduction of the total $\mathrm{CO}_{2}$ emissions in California. As the figure shows, the amount of reduction will depend on the overall performance of heat pumps and fossil based power plants.

Effect of hypothetical replacement of natural gas heaters with heat pumps on the total NOX, $\mathrm{CO}$ and $\mathrm{CO}_{2}$ pollutant emissions due to domestic heating in San Francisco Bay Area Air Basin and combined South Coast and San Diego Air Basins are shown in Figures 13 through 15 and 16 through 18 respectively. The trends are very similar to the figures 11 through 12 for California. Figures showing the separated effects of replacement of gas water heaters with heat pump water heaters, and gas space heaters with heat pump space heaters for California and the above-described.urban areas are presented in Appendix $A$.

Figures 19, 20 and 21 show the effect of percentage of fossil fuel in the generation $\mathrm{mix}$ on the total $\mathrm{NOx}, \mathrm{CO}$ and $\mathrm{CO}_{2}$ emissions from replacement of gas heaters with electric heat pumps. The curves have been produced for an average heat rate of $10,000 \mathrm{Btu} / \mathrm{KWH}$, three values of COP and the corresponding natural gas energy source emission factors produced in section 5. In these figures, the horizontal axis shows the total share of fossil fuels in the generation mix. Current levels of emissions for the corresponding air pollutants from natural gas heaters are also shown in each figure.

Two scenarios of $10 \%$ and $20 \%$ conversion have been considered in production of the above graphs. The figures show that as we increase the share of fossil fuels in the generation mix, the source pollutant emissions of heat pumps will increase. Increase in COP results in reduction of the pollutants. By increasing the conversion rate from $10 \%$ to $20 \%$ for the same share of fossil fuels 
in the generation $\mathrm{mix}$ and the same COP, annual NOx emissions will increase, and $\mathrm{CO}$ and $\mathrm{CO}_{2}$ emissions will decrease. The data for 1989 California generation mix are clearly marked. With the current California mix, as we concluded before, conversion to heat pump heating will increase the NOx emissions and reduce the $\mathrm{CO}$ and $\mathrm{CO}_{2}$ emissions in California. Improvements in power generation efficiency (lower heat rates) will reduce the overall emissions of pollutants from heat pumps in California.

Figures 19 through 21 were produced using the natural gas emission factors for electricity generation. The tacit assumption here is that if the electricity demand goes up due to the heat pump application, the marginal generation will mostly be from natural gas. Considering that almost all new plants use natural gas as their major fuel in California, and the fact that SAQMD will be requiring the same standards for all fossil fuel boilers supports this assumption at this stage. 


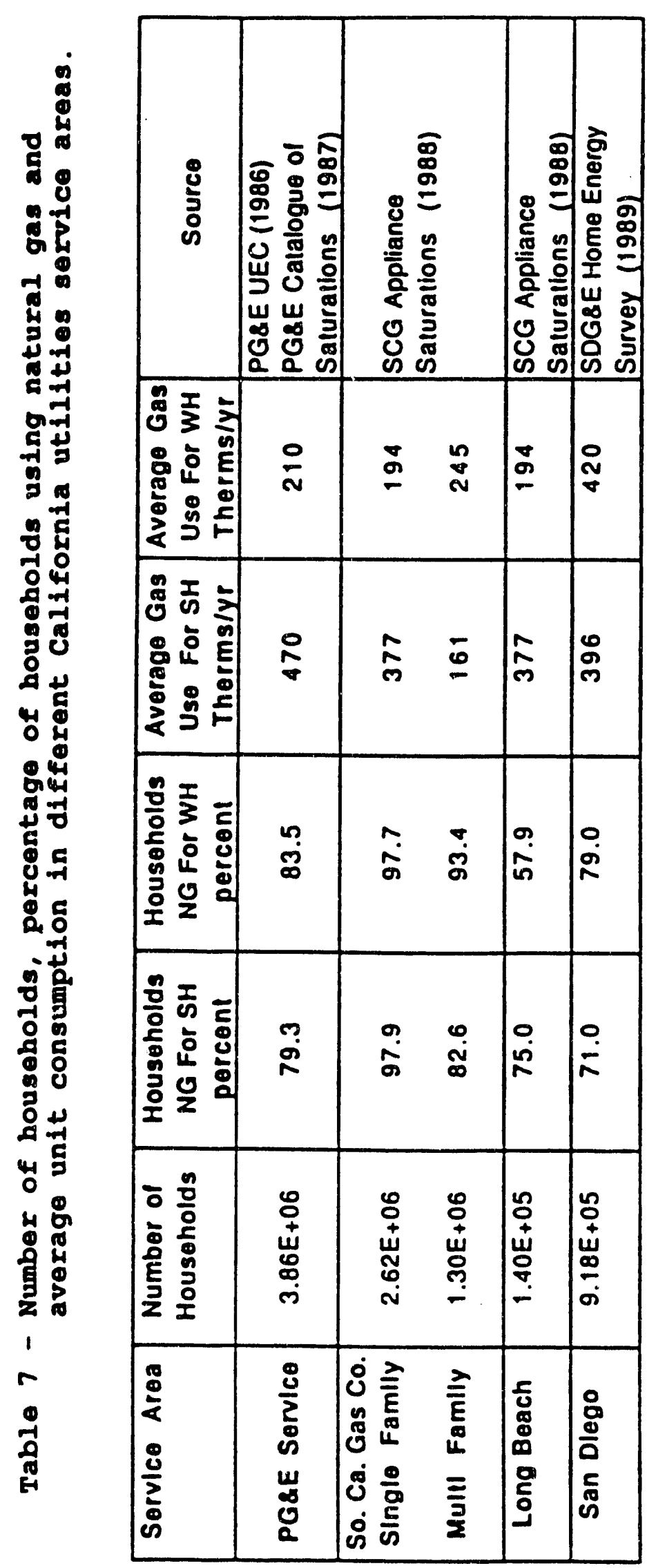

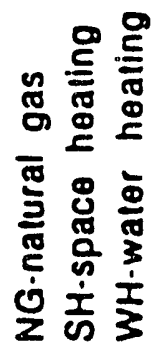




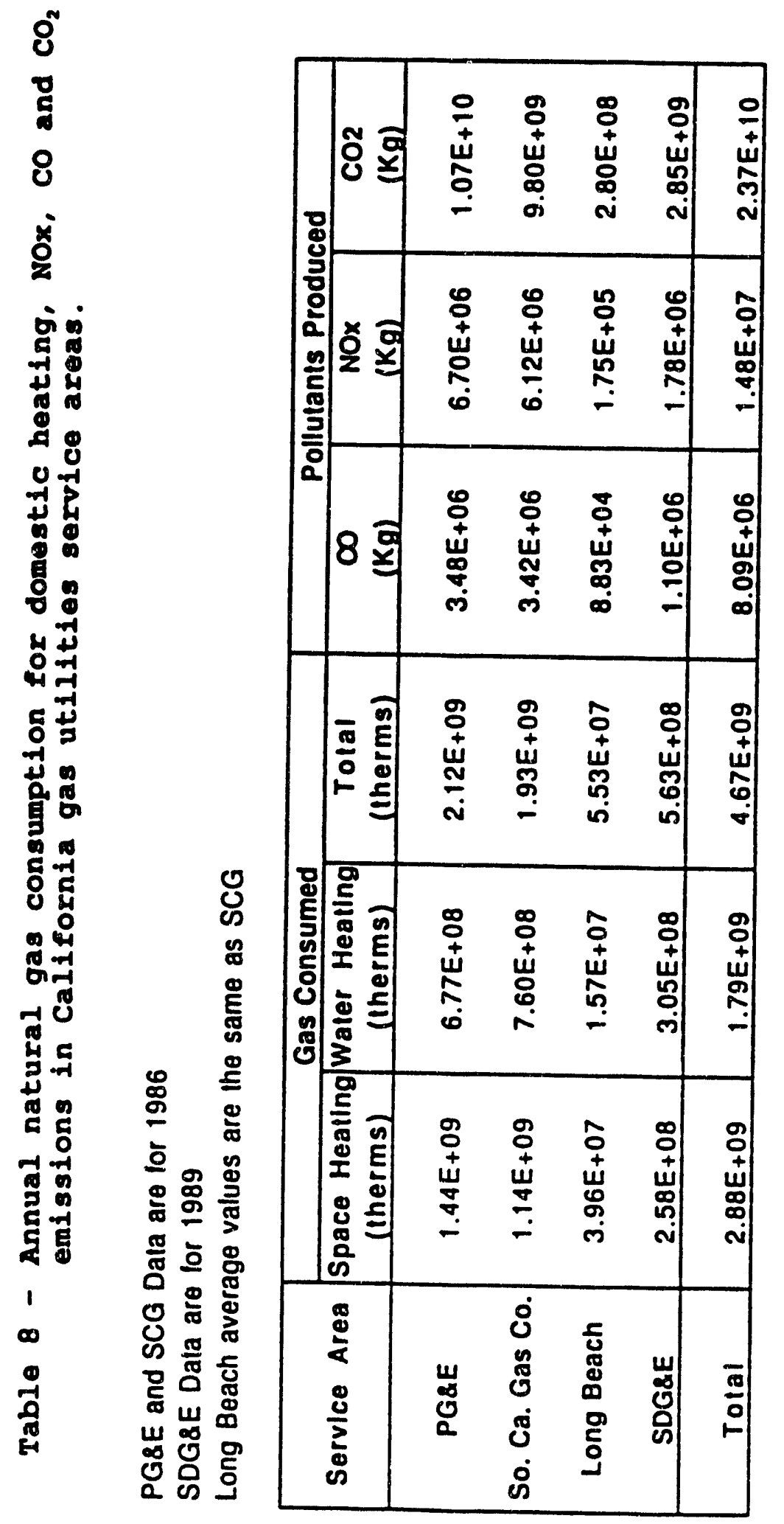




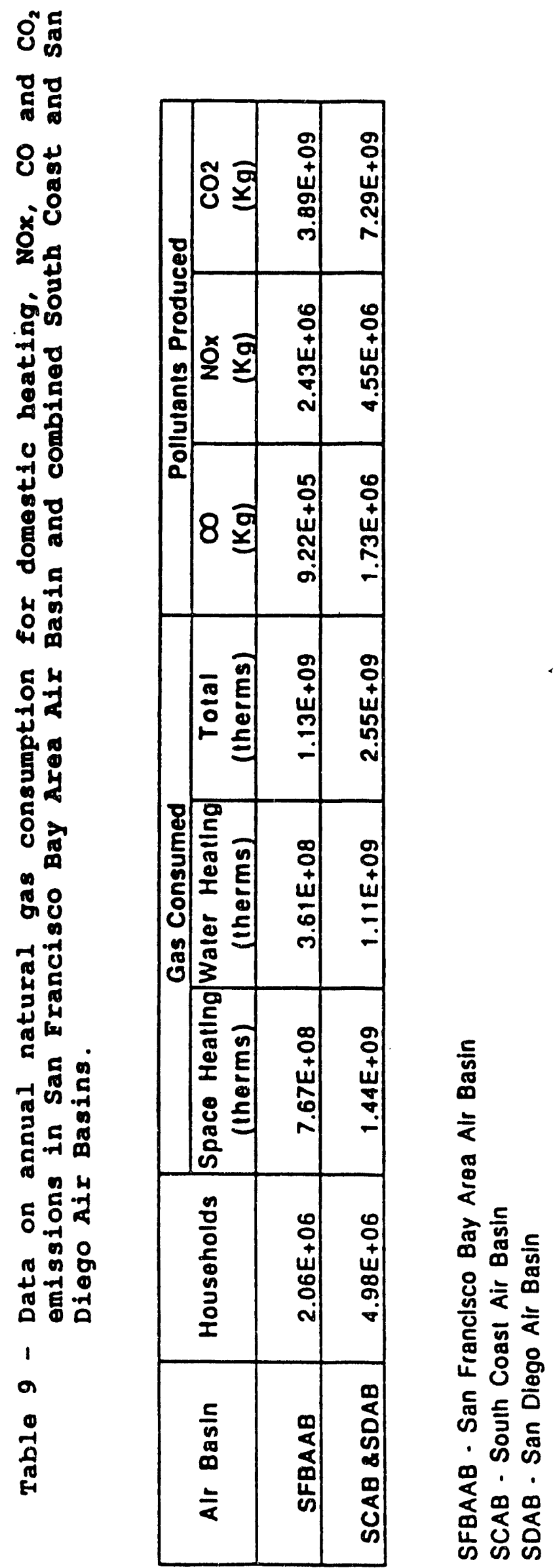




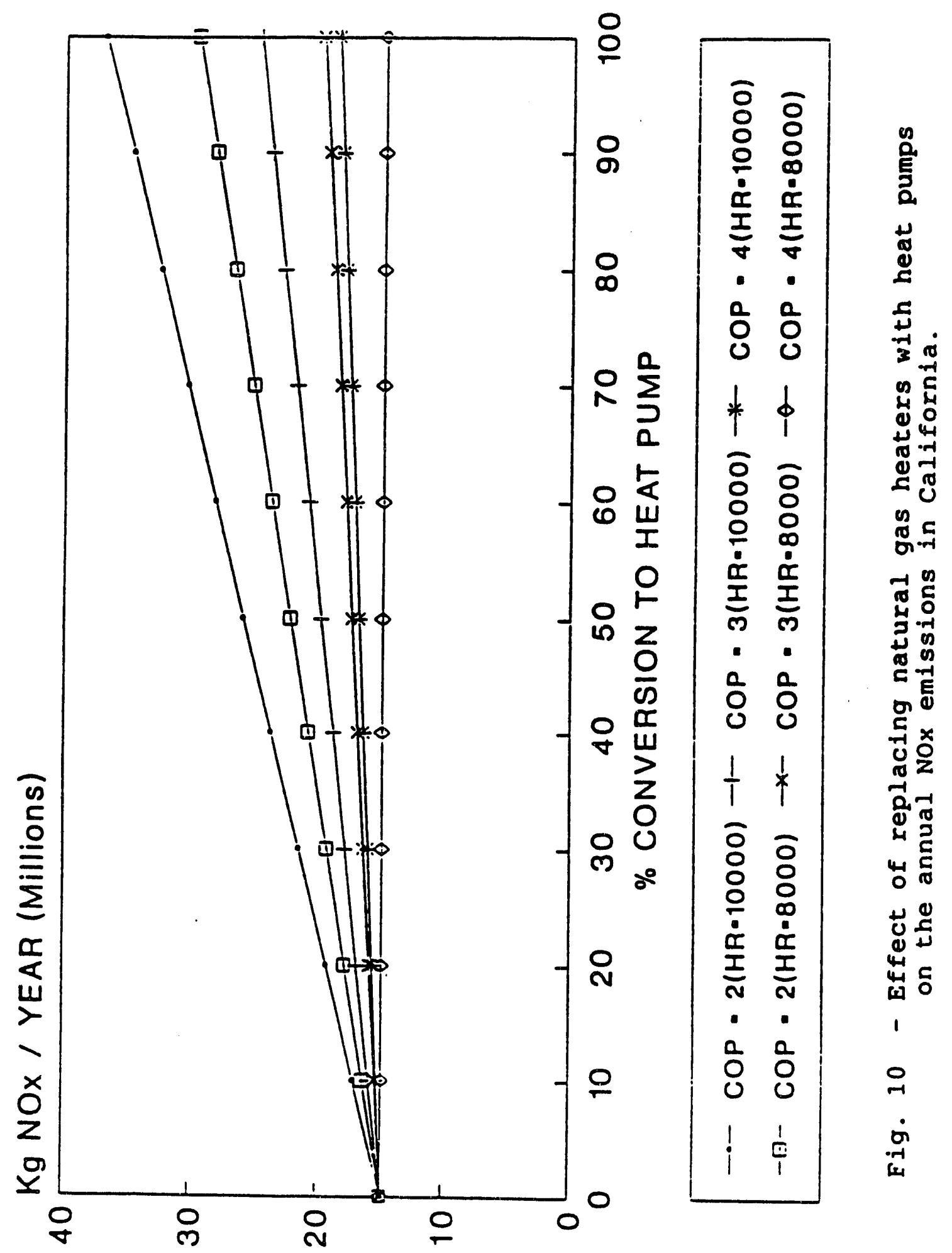




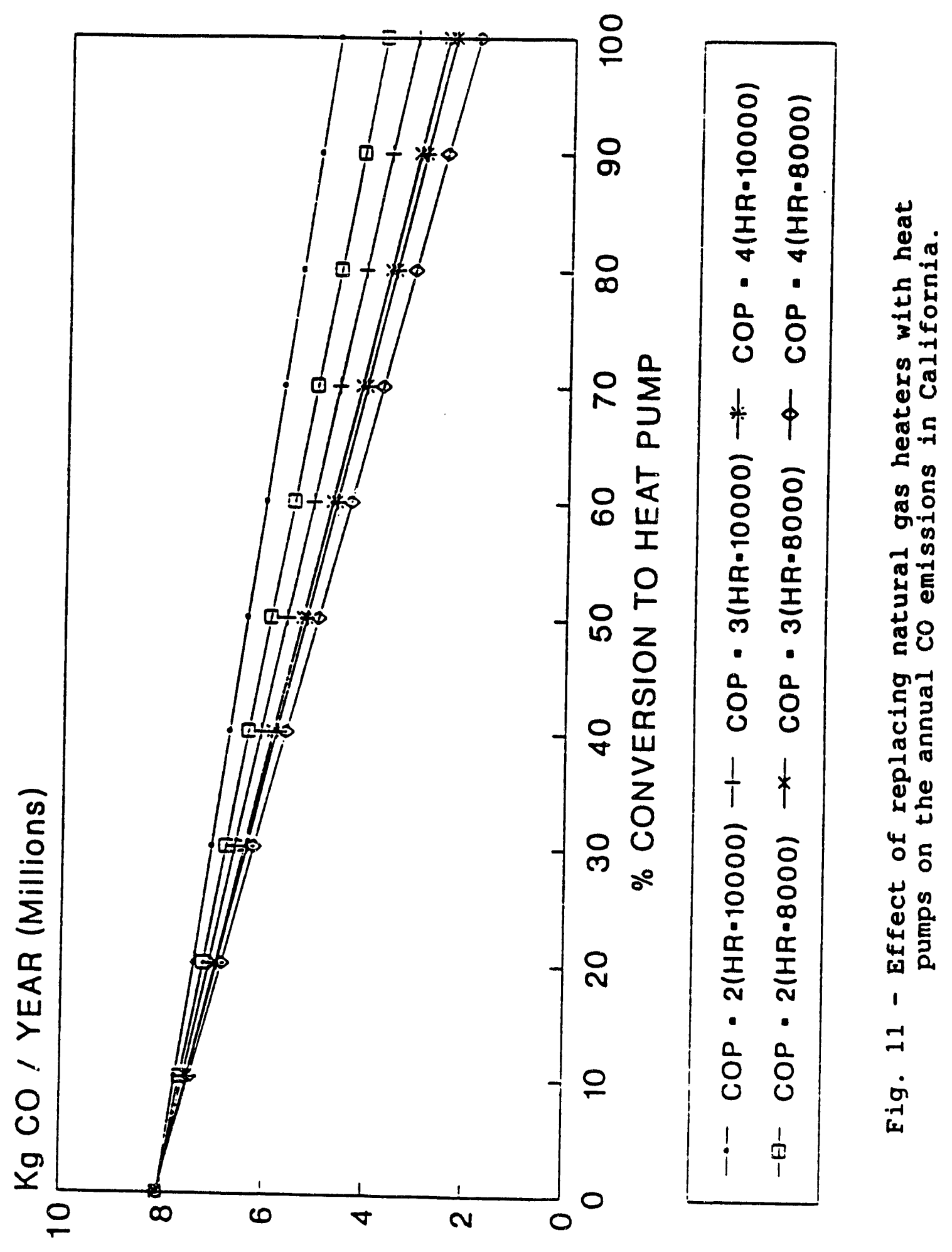




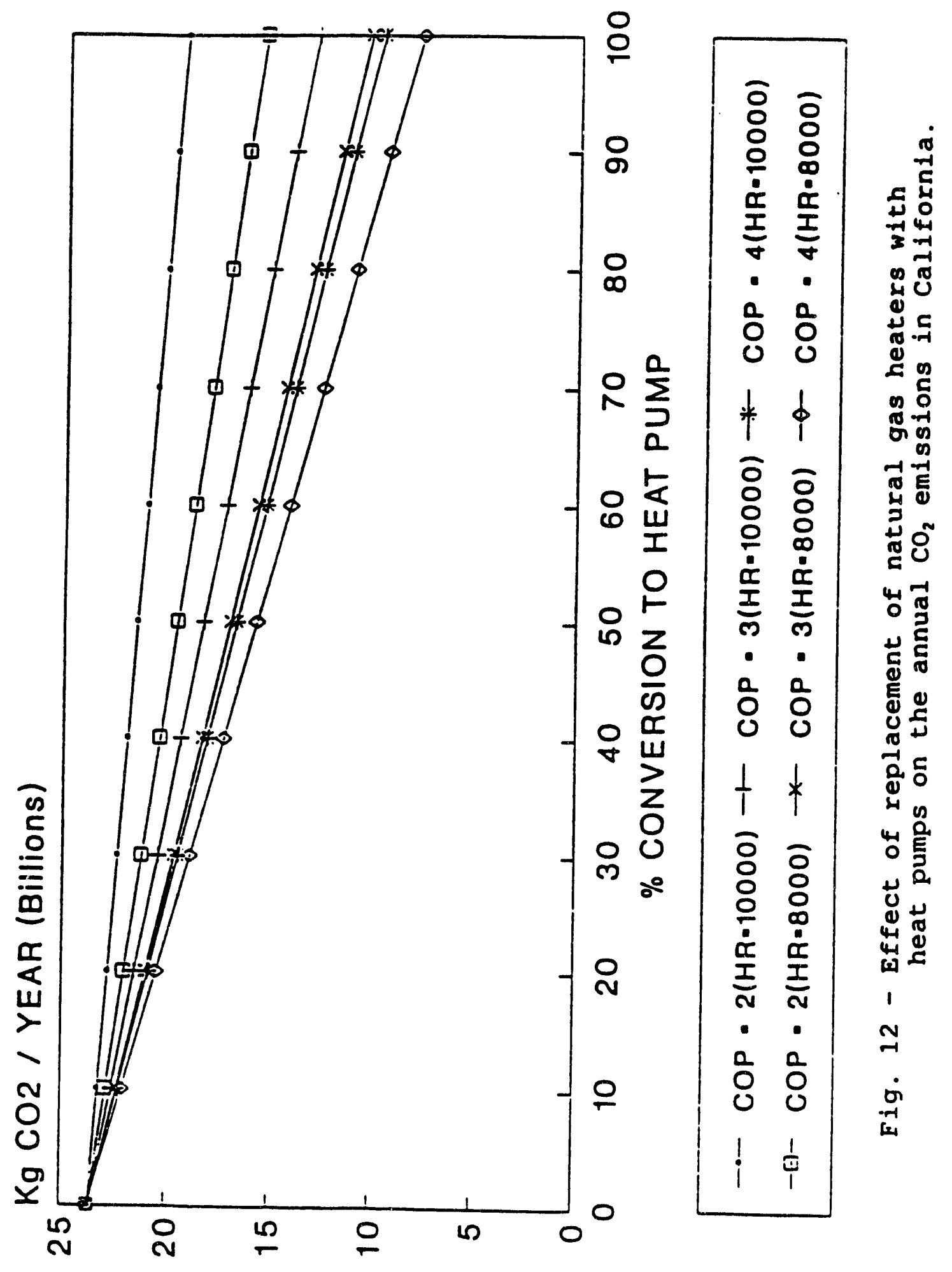




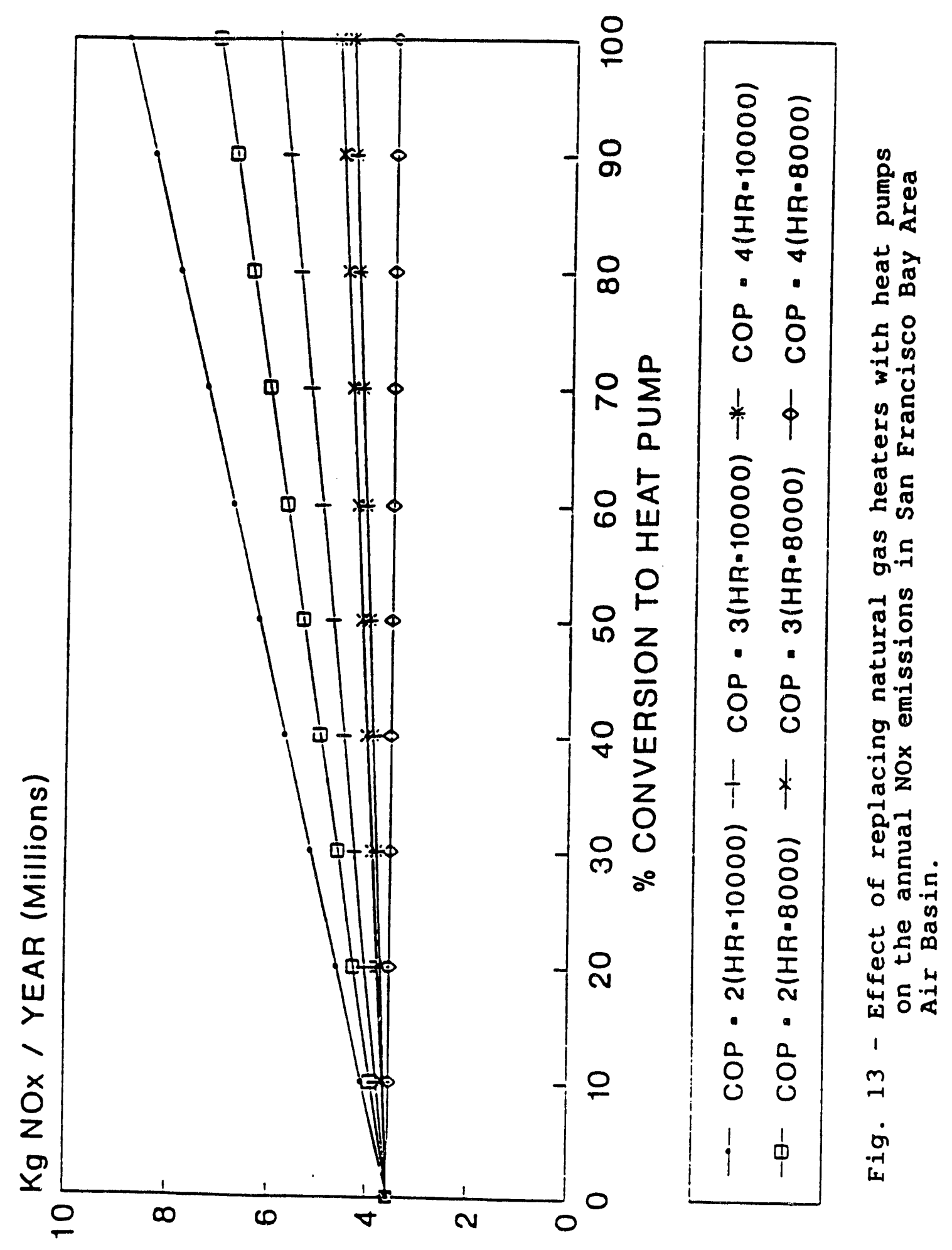




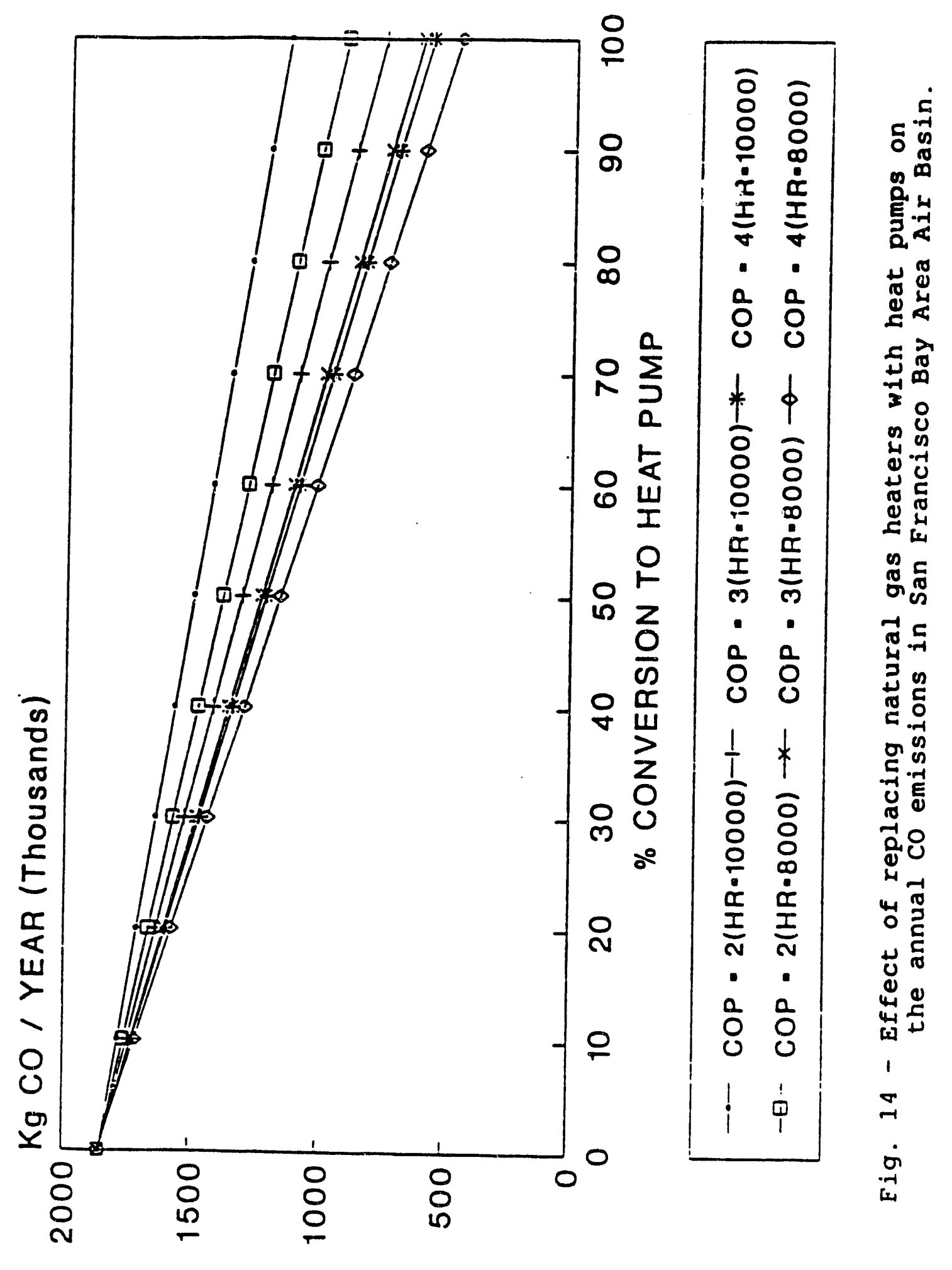




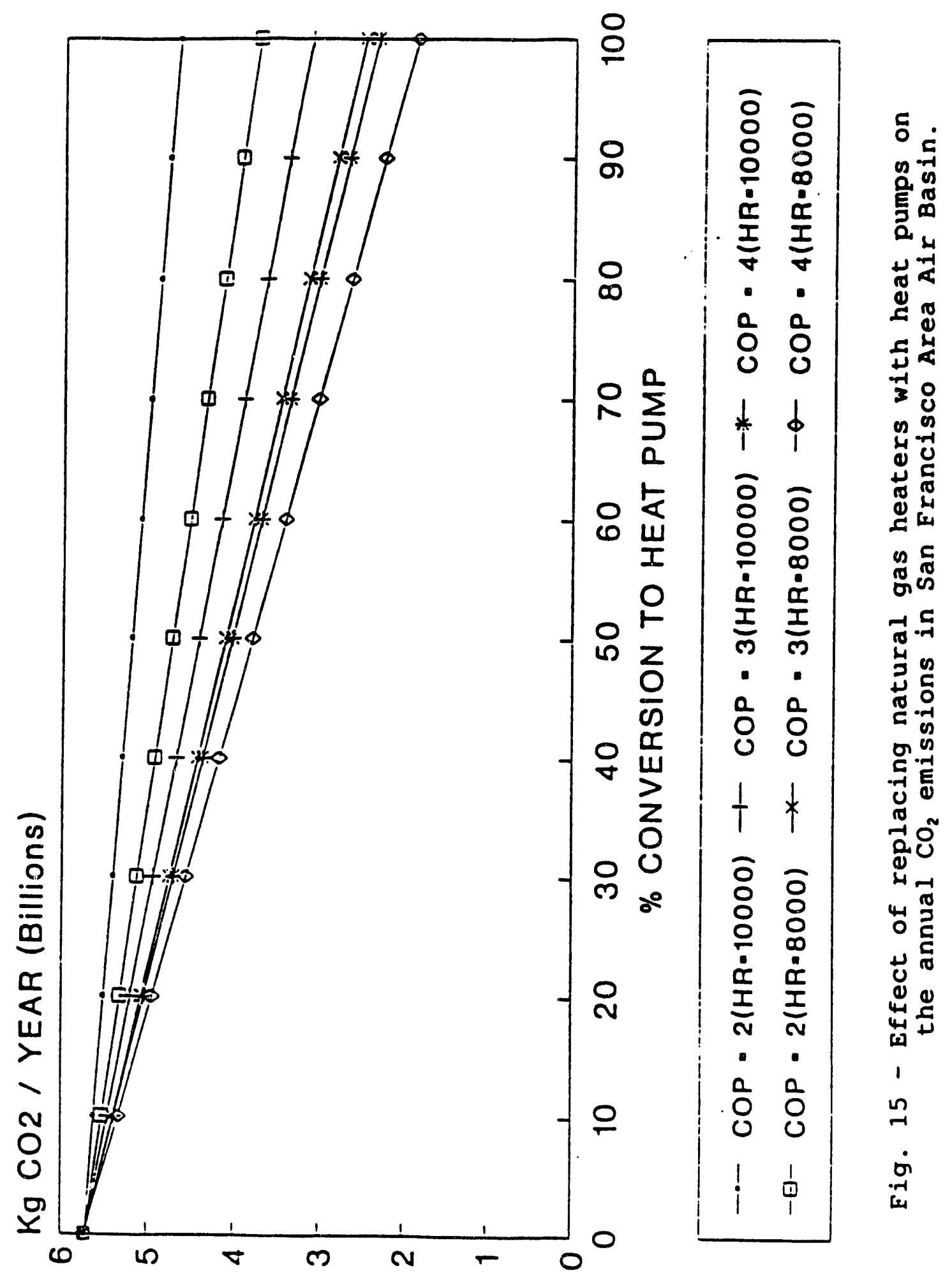




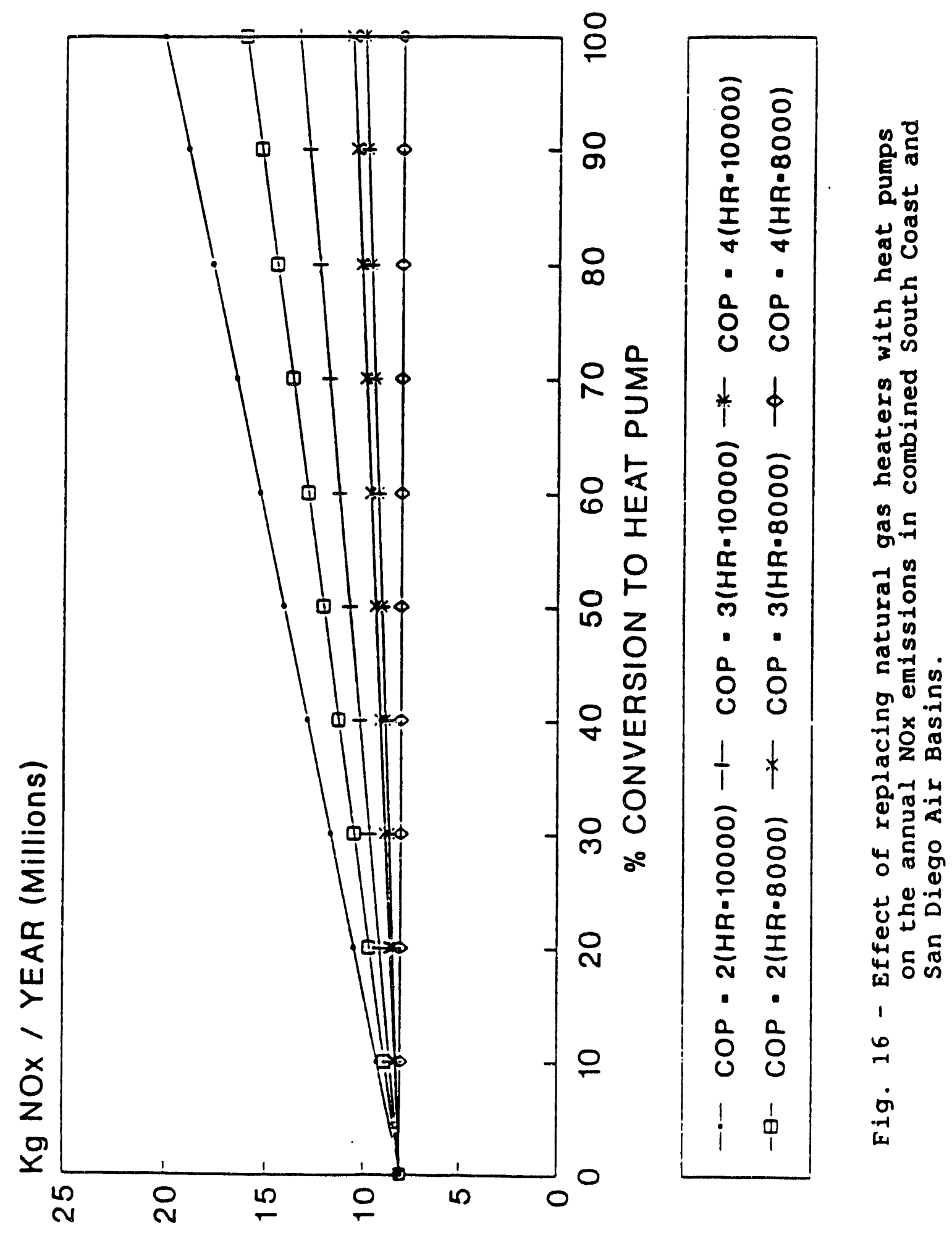




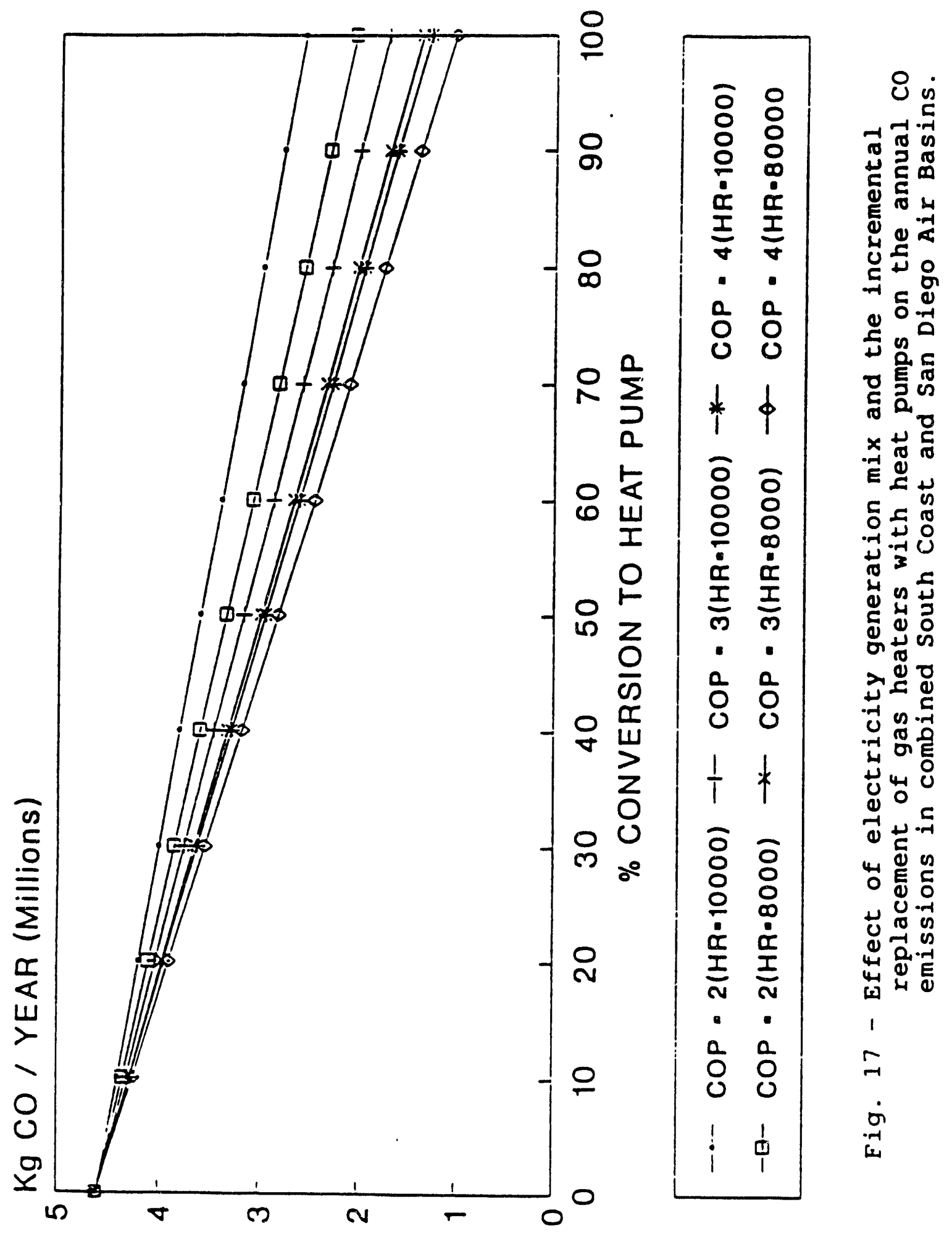




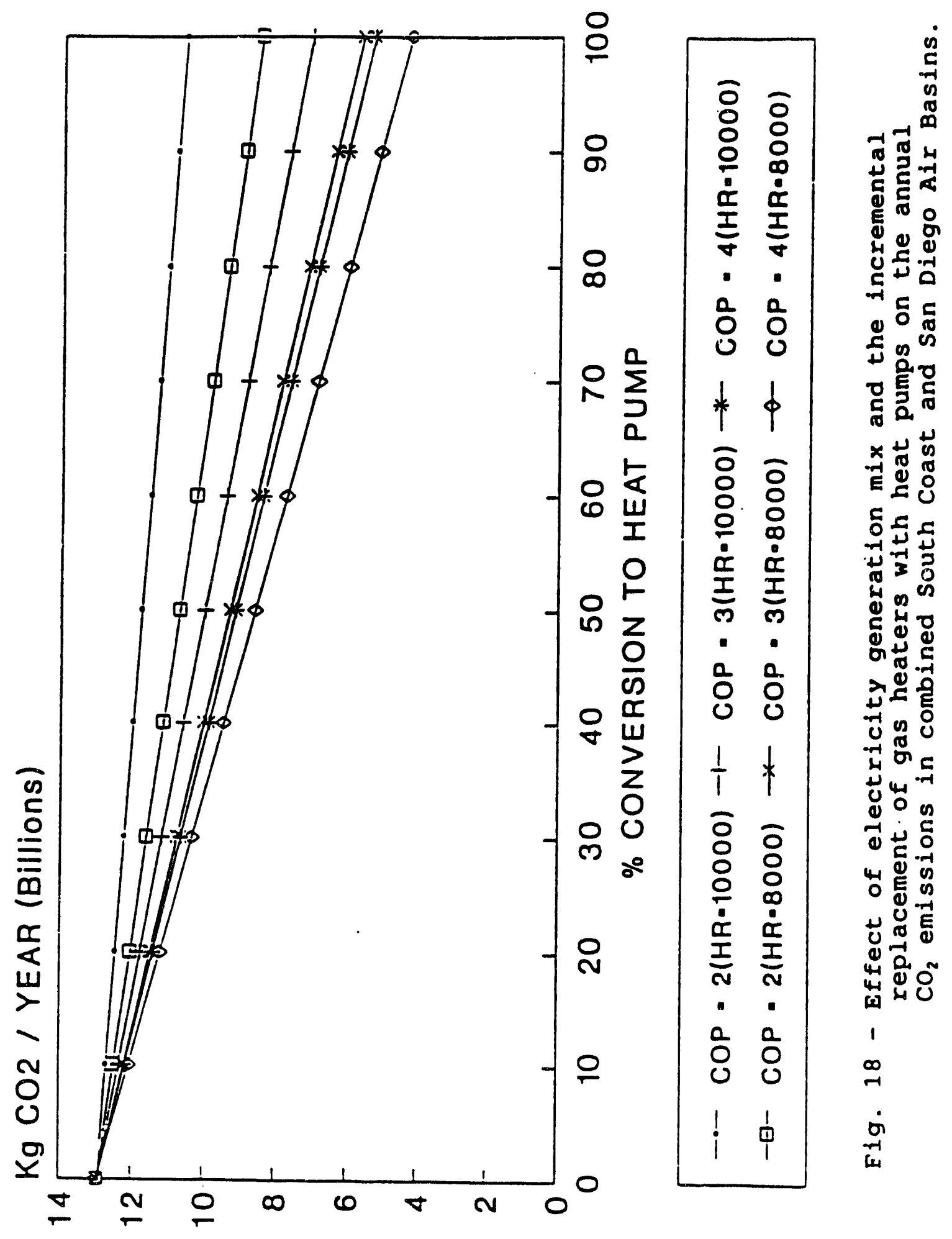




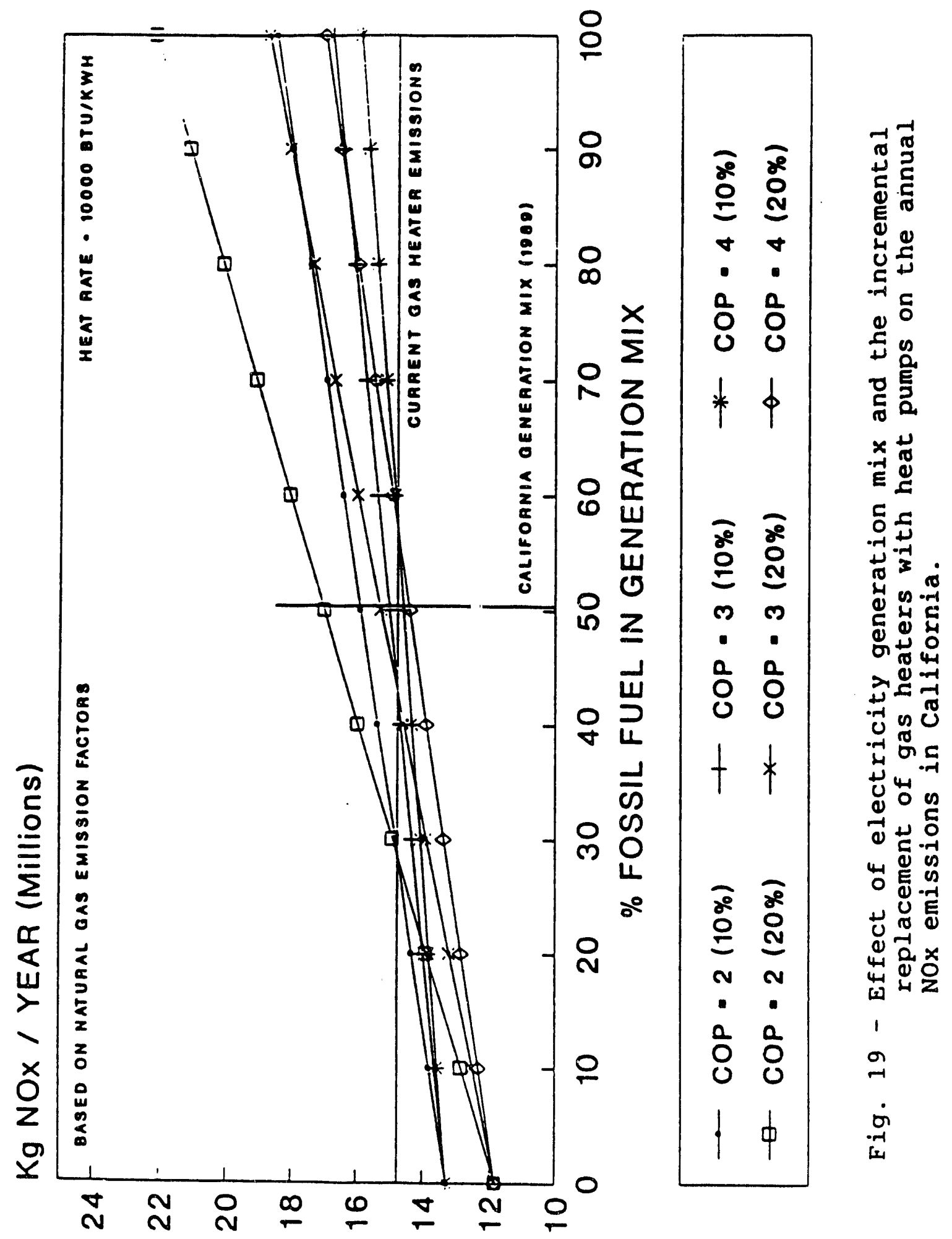




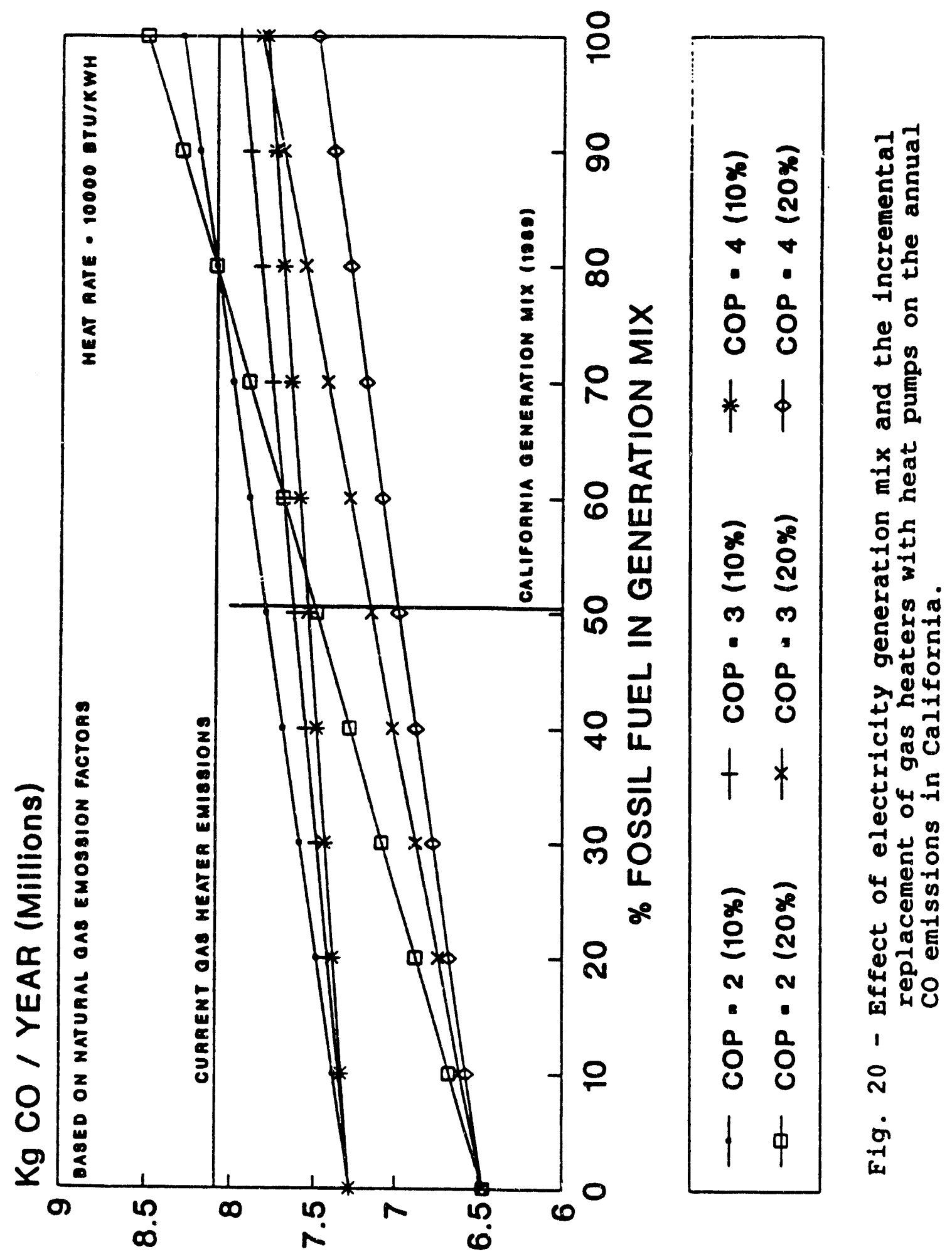




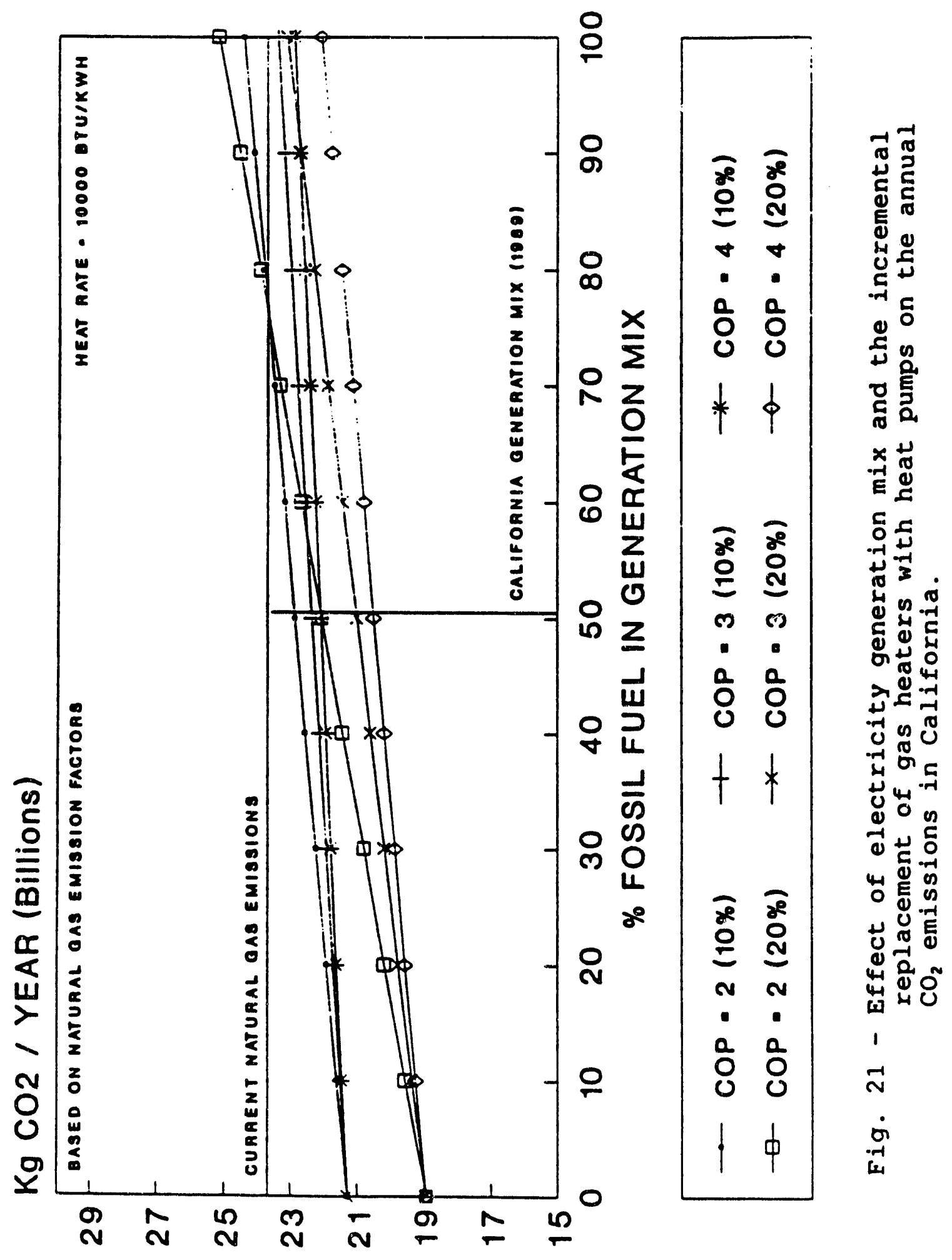




\section{7 - DISCOSSION, CONCLOSIONS, AND RECOMNENDATIONS}

The analysis and data presented in this report is an overall and first step investigation of the energy source efficiency and pollutant emissions of gas heaters and electric heat pump heaters. The emissions considered here are due to the operation of these appliances and limited to those emitted from natural gas combustion. As a result of this limitation, sulphur and particulate emissions which are usually a result of heavy oil and coal burning have not been dealt with here. Major reasons behind this limitation are that heavy oil and coal constitute a minor share of the electricity generation mix in California, and the fact that there is a clear cut distinction between gas heaters and electric heat pump heaters in this regard. Another factor that should be considered in the environmental evaluation of these heaters is the fact that gas heaters emit the pollutants at low elevations in populated areas, while electric power plants are usually located in more remote and rural areas, and emit the pollutants at higher elevations. A detail dispersion study may reveal noteworthy information on the effective concentration of these pollutants in various areas in California. Finally, the environmental effect of CFCs which are the main working fluids in heat pumps is noteworthy and deserves attention in further study of the subject. A more comprehensive investigation should involve comparison of air pollutant emissions and dispersion (and probably other forms of pollutants) considering the life cycle of these appliances and electric power plants.

A major factor in selection of any appliance as far as a consumer is concerned is cost. Again, this report has not dealt with the issue of cost comparison and cost/benefit analysis of gas heaters and heat pump heaters. Such an analysis will be a further extension of the present project. 


\section{Conclusions:}

Some of the major conclusions from this preliminary work can be summarized as follows:

1 - Based on the results shown in Fig. 2,

a - Current technology electric heat pumps utilizing electricity from an average efficiency power plant (HR of about $10,000 \mathrm{Btu} / \mathrm{KWH})$ are about 10 to 258 more efficient compared to an average efficiency natural gas heater.

b - Combination of advanced electric heat pumps (COR > 4) and advanced high efficiency power plants can be approximately twice as efficient as an average natural gas heater, and over 508 more efficient than advanced high efficiency natural gas heaters.

c - Wile gas heaters have practically reached their top efficiency limit, improvements in electricity generation efficiency and heat pump technology can result in substantial savings of natural, non-renewable energy resources.

2 - Based on the results shown in Fig. 3:

a - If $100 \%$ of electricity to be used by heat pumps is produced from natural gas, NOx emission factor of heat pumps will be substantially (more than twice) higher than natural gas heaters. Because NOx standards for utility boilers using fuel oil and coal are higher than natural gas, this conclusion will be equally true for all fossil fuels as an energy source for electricity generation.

b - Combination of advanced heat pumps and advanced high efficiency electricity production will reduce the emission factor of heat pumps, but even then the heat pumps will not be competitive with current technology gas heaters in this respect.

c - Low Nox burners develrped for application in gas heaters 
which have NOx emissions of about or less than $1 / 5$ of current SCAQMD standards will alter the above conclusions ( $a$ and $b$ above) even more in favor of natural gas heaters.

3 - Based on the results shown in Figures 4 and 7 , and manufacturer's data (Table 2) heat pump heaters produce much less (less than 50\%) effective co emissions compared to natural gas heaters. Improvements in electricity generation efficiency and heat pump technology will tilt the above conclusion in favor of heat pump. Improvement in $c 0$ emissions in advanced technology gas heaters have not been consistent (Table 2).

4 - Considering the current U.S. generation $\operatorname{mix}($ Fig. 6), heat pumps have two to four times higher effective Nox emissions compared to natural gas heaters. While improvements in electric generation efficiency and heat pump COP will reduce the NOx emission factor (Fig. 3), still the emission factor of heat pumps will be substantially higher than the emission factor of gas heaters. NOx emission levels reported for low NOx gas burners (Table 2) which are substantially below SCAQMD standards tilt this conclusion even more in favor of gas heaters.

5 - Considering the current California generation mix (Fig. 6), NOx emission factor of heat pumps will be slightly higher but comparable to SAQMD NOx standards for gas heaters. Advanced heat pumps (COP $>4)$ and also advanced high efficiency electricity generation will improve the NOx emission factor of heat pumps in California and make it competitive with current regulated gas heaters. Lower NOx emission standards and substantial reduction in NOx emissions from gas heaters, as has been reported for low NOx burners, will put the gas heaters at an advantage in this respect.

6 - Considering the current California electricity generation mix 
(Fig. 8), heat pumps have $\mathrm{CO}_{2}$ emission factors of about $50 \%$ of natural gas heaters. Advanced technology gas heaters, heat pumps and electricity generation have an improving effect on $\mathrm{CO}_{2}$ emission factors (Eig. 5), but the ratio of the emission factors will remain approximately the same.

7 - With the present technology heat pumps and current electricity generation heat rate (about $10,000 \mathrm{Btu} / \mathrm{KWH}$ - 348 efficiency). replacement of gas heaters with heat pumps to any extent will increase total NOx emissions, and reduce total $\mathrm{CO}$ and $\mathrm{CO}_{2}$ emissions in California. Combination of advanced high Cop heat pumps (COP $>4$ ) and high efficiency power plants (HR $<8,000$ Btu/KWH) will slightly reduce the total NOx emissions and also improve (reduce) $\mathrm{CO}$ and $\mathrm{CO}_{2}$ emissions in California.

\section{Recomendations:}

This has been a limited exploratory project and a first step in comparative evaluation of the efficiency and environmental effects of electric heat pumps and gas heaters. Substantial research and analysis is required to fully evaluate and compare the energy efficiency and environmental effects of these appliances. The following are some recommendations in this regard:

1 - Energy efficiency and environmental effects of various heating and cooling appliances in conjunction with each other need to be evaluated.

2 - Effect of year round climate and building shell on the energy efficiency and emission factors of these appliances need to be simulated.

3 - When analyzing the effect of replacement of gas heaters with heat pump heaters, a more realistic approach will be to consider the mix of electricity generation in different regions, and to consider the change in the generation mix due 
to the conversion.

4 - Efficiency and pollutant emissions in the life cycle of various heating and cooling appliances will probably produce very valuable information on this subject. 


\section{8 - REFERENCES}

Adams, C.W. 1982. Performance results of the Lennox pulse combustion furnace field trials. Proceedings of the symposium on Pulse Combustion Applications, Vol. I, GRI Report, GRI 82/0009.3.

ACA. 1991. Cogeneration and energy conservation for the 90's. Proceedings of Third Annual Technical Conference, Sponsored by the American Cogeneration Association. March 18-19, 1991, Mesa, Arizona.

Ahlby, L. and Hodgett, D.I. 1990. Compression-absorption heat pumps. Proceedings of the Heat Pump Conference, March 12-15, 1990, Tokyo, Japan.

ARI. 1991. Directory of certified unitary air conditioners, unitary air source heat pumps, sound rated outdoor unitary equipment. Feb. 1991. Air Conitioning and Refrigeration Institute.

CEC. 1989. Electricity, 1988 Report. California Energy Commission.

CEC. 1990a. Inventory results. CR-90, California Energy Commission, March 16, 1990.

CEC. 1990b. California Energy Commission Data obtained from CEC staff.

CEC. 1990c. Energy efficiency, California Energy Commission Report P. 400-90-003.

CFR. 1989a. Code of Federal Regulations 40CFR60.

CFR. 1989b. Code of Federal Regulations 10CFR400 to 499.

Chen, F.C. Mei V.C. and Lavan, 2. 1988. Analysis and application of heat pumps. Paper presented at the 1988 ASME Winter Annual Meeting, Nov. 27 - Dec. 2 .

Dickenson, R.L., Vejtasa, S.A. and Korens, N. 1990. Future cogeneration technologies. EPRI Report CU-6795.

Diehl, H. 1989. Toward an environmentally sound energy supply, development in the Federal Republic of Germany. Proceedings of 1989 Conference on Technologies for Producing Electricity 
in the Twenty First Century, San Francisco, Oct. 30 - Nov. 2, sponsored by EPRI.

Duffy, T.E., Schneider, P.H., Campbell, A.H. and Evensen, O.E. 1987. Advanced high performance steam systems for industrial cogeneration. Final Report for DOE Contract \#DE-AC0285GE40746. Prepared by Solar Turbines, Inc., SR87-R-5323-20.

EIA. 1990. Energy Information Administration, Annual Outlook for U.S. Electric Power.

EPA. 1985. Compilation of air pollutant emission factors. 4th Ed. EPA Report AP-42.

EPRI 1989. Conference on Technologies for Producing Electricity in the Twenty First Century. Proceedings of the Conference held in San Francisco, Oct. 30 - Nov. 2, 1989, sponsored by the Electric Power Research Institute (EPRI), Palo Alto, CA.

EPRI 1990. Residential heat pump marketing guidebook. EPRI Report CU-7106.

French C.E.; Jacob, E.E.; Klausing, T.A. and Roose, T.R. 1989. Gas Research Institute Residential, reciprocating natural gas engine vapor-compression heat pump. Proceedings of the 1989 International Gas Research Conference, Tokyo, Japan, November 1989.

GAMA. 1988. Consumers' directory of certified efficiency ratings for residential gas and water heating equipment, Gas Appliance Manufacturers' Association.

Ganji, A.R. and Wheeler, A.J. 1989. A Survey on the state of the technology, research and development of electric water heaters. PG\&E Research and Development, Report 008.1-89.11.

Ganji, A.R. 1991. Environmental and energy evaluation of residential gas and heat pump heating. Published in AES-Vol. 25/HTD - Vol. 191, Second Law Analysis - Industrial and Environmental Applications, ASME 1991.

Hall, R.E., Wasser, J.H. and Berkau, E.E. 1974. A study of air pollutants from residential heating systems. EPA-650/2-74003 . 
Harnish, J.T. 1991; Proknow, D.W; Jacob, E.E.; Klausing, T.A.; French, C.E. and Nowakowski, G. 1991. Residential gas heat pump design and development. Presented at the ACA Conference on Cogeneration and Energy Conservation for the 90's, Mesa, Arizona. March 18-19.

International Energy Agency (IEA) . 1982. Heat Pump Systems, a Technology Review, Organization for Economic Co-Operation and Development (OECD), Paris.

McLinden, M.0. and Klein, S.A. 1985. ASHRAE Technical Data Bulletin, TDB-24, vol. 1 .

Minden, A.C. and Kennedy, J.M. 1987. Fiber matrix burner commerial storage water heater. GRI Report GRI-87/0302.

Nelson, I.W. 1989. Residential comfort. ASHRAE Journal, Vol. 31, No. 1, pp 21-24.

Ohuchi, Y. 1985. Development of a gas fired absorption heat pump. ASHRAE Technical Data Bulletin, TDB-24, vol. 1.

Pam, R.I. and Kesselring, J.P. 1987. Burner survey for high efficiency gas fired heating units. GRI Report GRI-84/0056.

PG\&E. 1986. Pacific Gas and Electric unit energy consumption of residential appliances. (R.S. Barneo and C.R. Loi Principal Investigators), Pacifil Gas \& Electric Co., San Erancisco, CA.

PG\&E. 1987. 1986 Residential appliance saturation survey catalog of saturations. Pacific Gas \& Electric Co., San Francisco, CA.

Phillips, B.A. 1985. High efficiency absorption cycles for residential heating and cooling. 20th Intersociety Energy Conversion Engineering Conference (IECEC), Vol. 2, pp 229-34.

Rao, A.D., Erancuz, V.J., Shen, J.C. and West, E.W. 1991. A comparison of humid air turbine (HAT) cycle and combined-cycle power plants. EPRI Report IE-7300.

SCG. 1988a. Appliance saturations and gas use in the single-family sector. (by J. Van Lieropend K.M. Parris), Southern California Gas Co.

SCG. 1988b. Appliance saturations and gas use in the multifamily sector. (by J. Van Lieropend K.M. Parris), Southern California Gas Co. 
Swain, J.C.; Klausing, T.A.; Lambert, J.E. and Trayser, D.A. 1986 . Design and test of an internal combustion gas engine for residential heat pumps. 1986 International Gas Research Conference, Toronto, Canada, Sept. 1986.

Thrasher, W.H. and DeWerth, D.W. 1975. Evaluation of the pollutant emissions from gas fired forced air furnaces. AGA Research Report No. 1503.

Thrasher, พ.H. 1986. Pulse combustion residential water heater. GRI $-86 / 0225$.

Thrasher, W.H. and DeWerth, D.W. 1979. Evaluation of the pollutant emissions from gas fired hot water and steam boilers. AGA Research Report No. 1525.

Traynor, G.W., Aceti, J.C., Apte, M.G., Smith, B.V. and Green, L.I. 1989. Macromodel for assessing residential concentrations of combustion generated pollutants: model development and preliminary predictions for $\mathrm{CO}, \mathrm{NO}_{2}$ and respirable suspended particles. Lawrence Berkeley Laboratory Report LBL-25211.

Urban, C.M., Dietzman, H.E. and Fanrick, E.R. 1989. Emission control technology for stationary natural gas engines. Journal of Engineering for Gas Turbines and Power, Vol. 111, pp. 369-374.

Whitlock, D.J., Eavors, S.F. and Reuter, G. 1982. Field tests on pulse combustion boilers for residential space heating and domestic water heating. Proceedings of the symposium on Pulse Combustion Application. Vol. I, GRI-82/0009.2.

Wood, B.D. 1982. Applications of Thermodynamics, 2nd Ed., Waveland Press, Prospect Heights, Illinois.

Zawacki, T.S., Zimmer, J.W. and Marciss, R.A. 1980. Research, development and demonstration of high efficiency gas fired water heaters. GRI Report GRI-80/0004. 


\section{APPENDIX A}

In this appendix, the following detail figures are presented:

I - Effect of replacing natural gas space heaters with heat pumps on the annual emissions of $\mathrm{NO}, \mathrm{CO}$ and $\mathrm{CO}_{2}$ in California, Figures $A-1$ through $A-3$.

II - Effect of replacing natural gas water heaters with heat pumps on the annual emissions of $\mathrm{NOX}, \mathrm{CO}$ and $\mathrm{CO}_{2}$ in California, Figures $A-4$ through $A-6$.

III - Effect of replacing natural gas space heaters with heat pumps on the annual emissions of $\mathrm{NOx}, \mathrm{CO}$ and $\mathrm{CO}_{2}$ in the San Erancisco Bay Area Air Basin, Figures A-7 through A-9.

IV - Effect of replacing natural gas water heaters with heat pumps on the annual emissions of $\mathrm{NOx}, \mathrm{CO}$ and $\mathrm{CO}_{2}$ in the San Francisco Bay Area Air Basin, Figures A-10 through A-12.

$V$ - Effect of replacing natural gas space heaters with heat pumps on the annual emissions of $\mathrm{NOX}_{1} \mathrm{CO}$ and $\mathrm{CO}_{2}$ in the combined South Coast and San Diego Air Basins, Figures A-13 through Fig. A-15.

VI - Effect of replacing natural gas water heaters with heat pumps on the annual emissions of $\mathrm{NOx}, \mathrm{CO}$ and $\mathrm{CO}_{2}$ in the combined South Coast and San Diego Air Basins, Figures A-16 through A-18. 


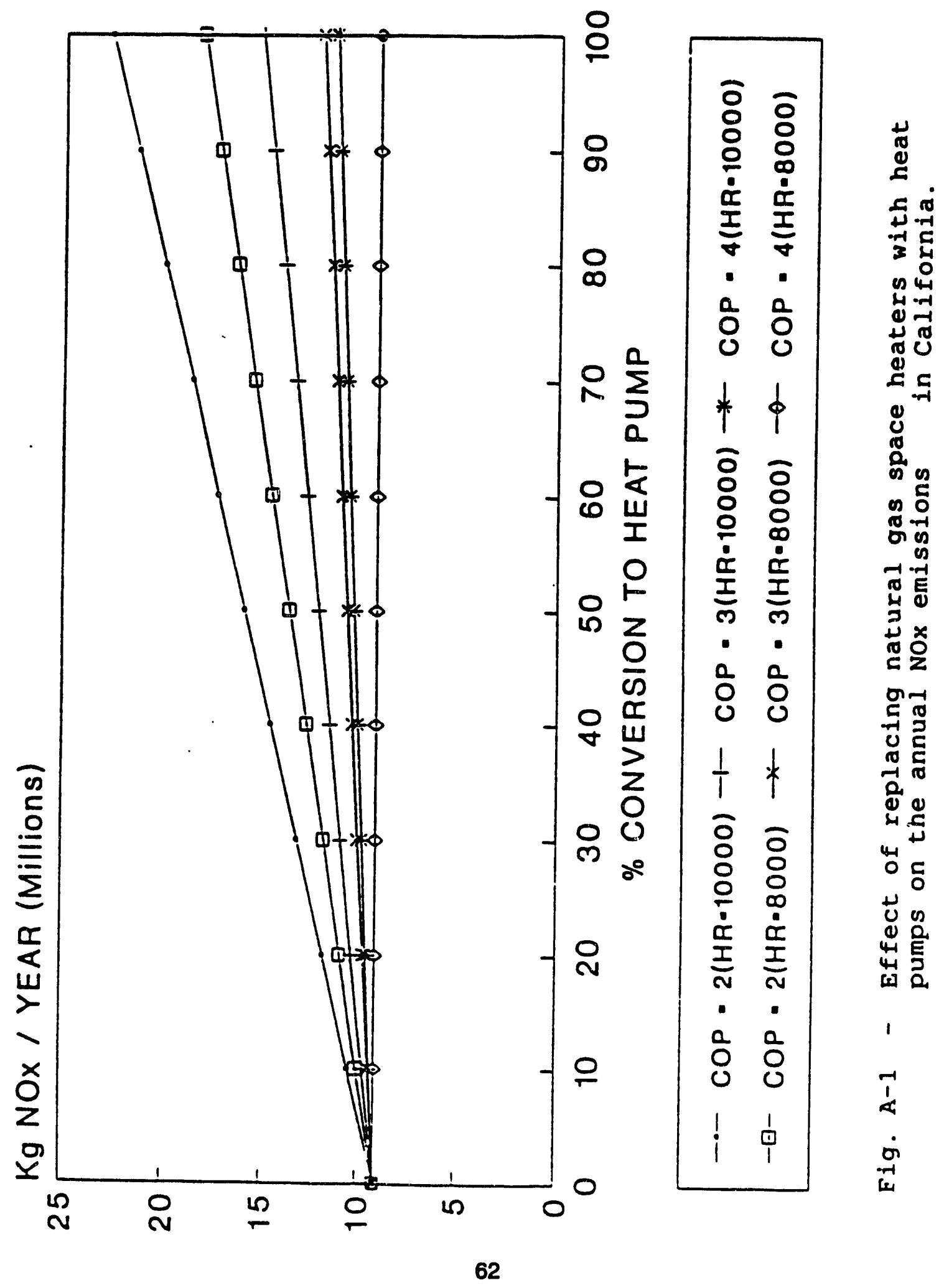




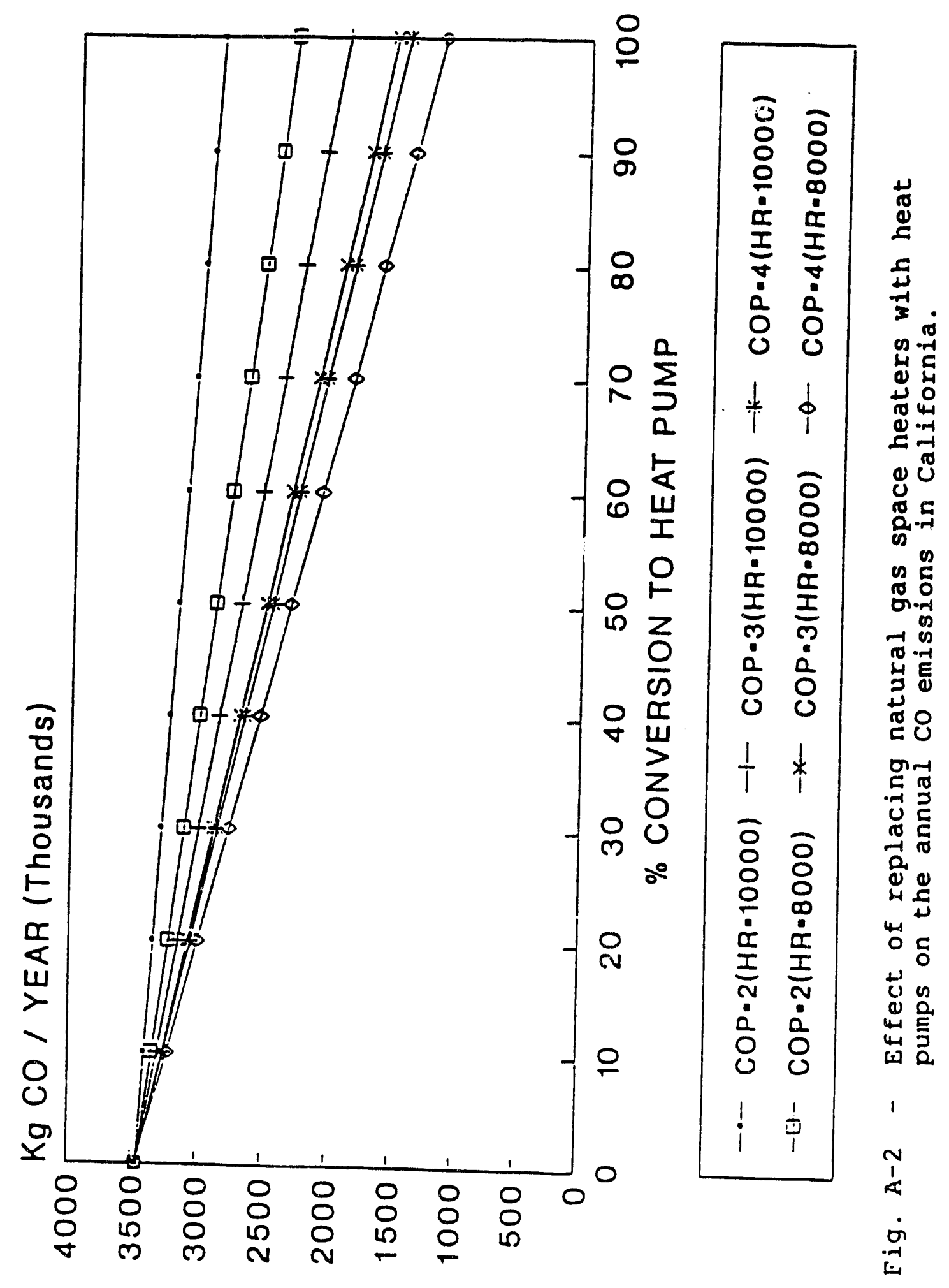




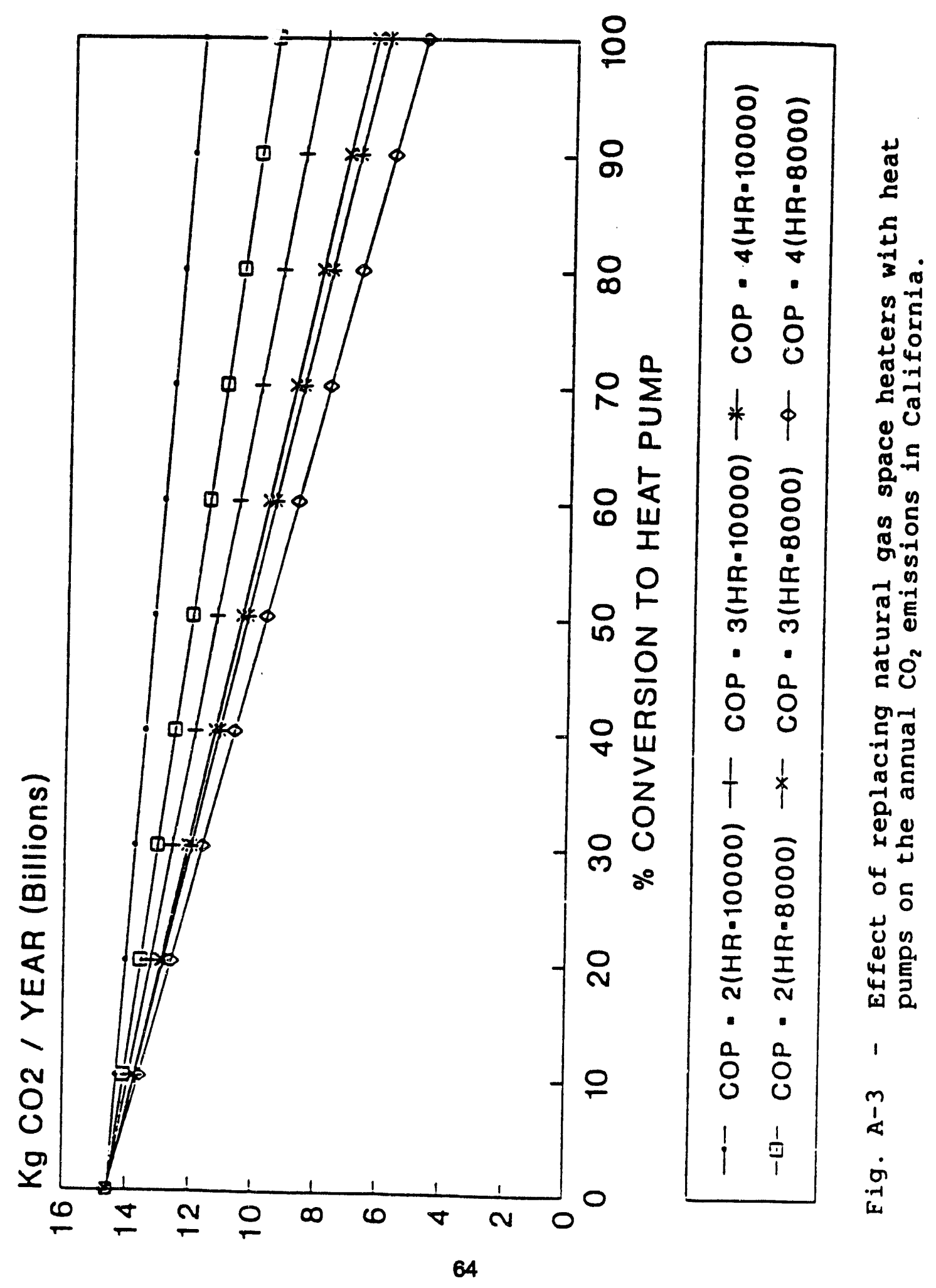




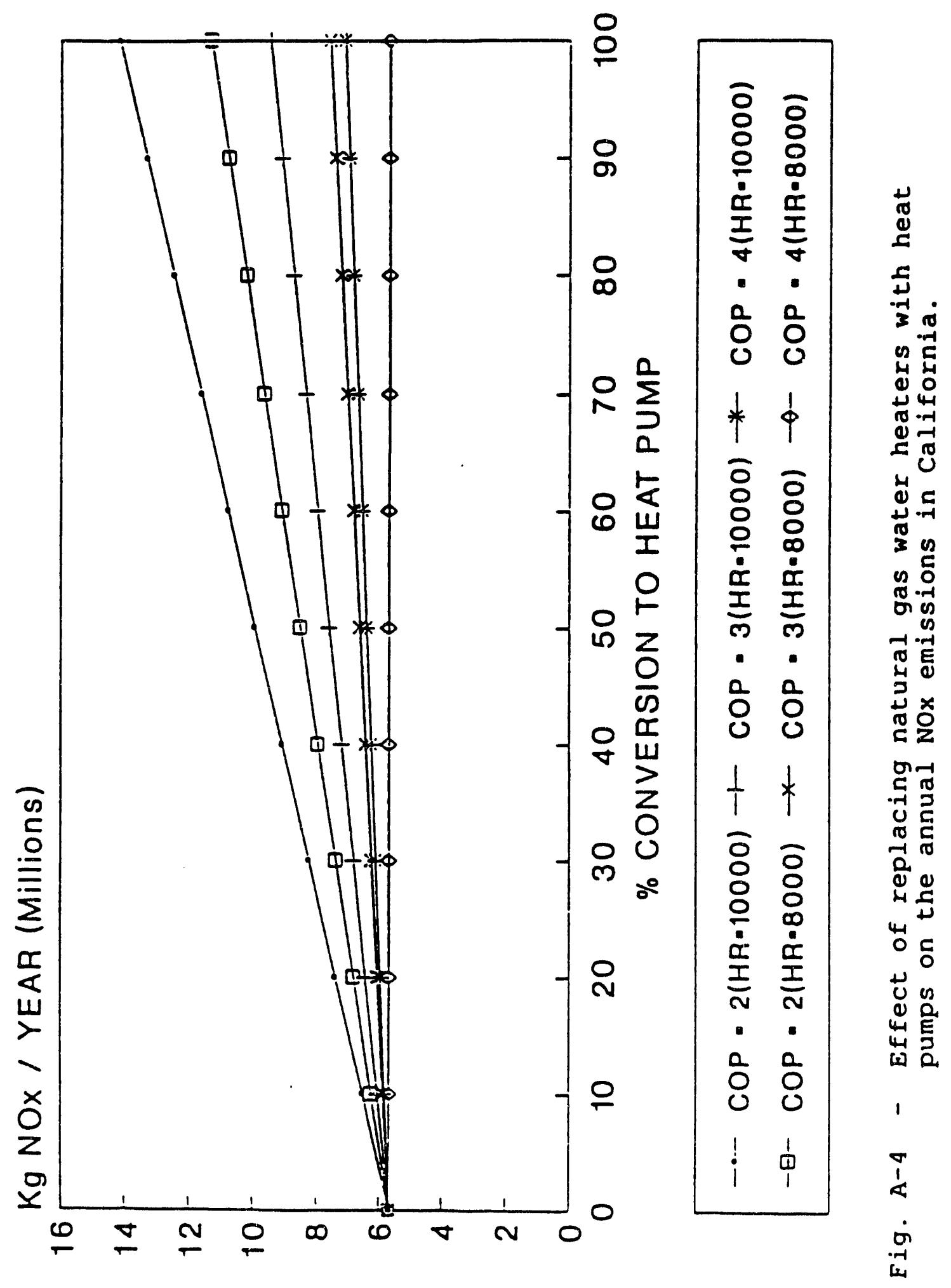




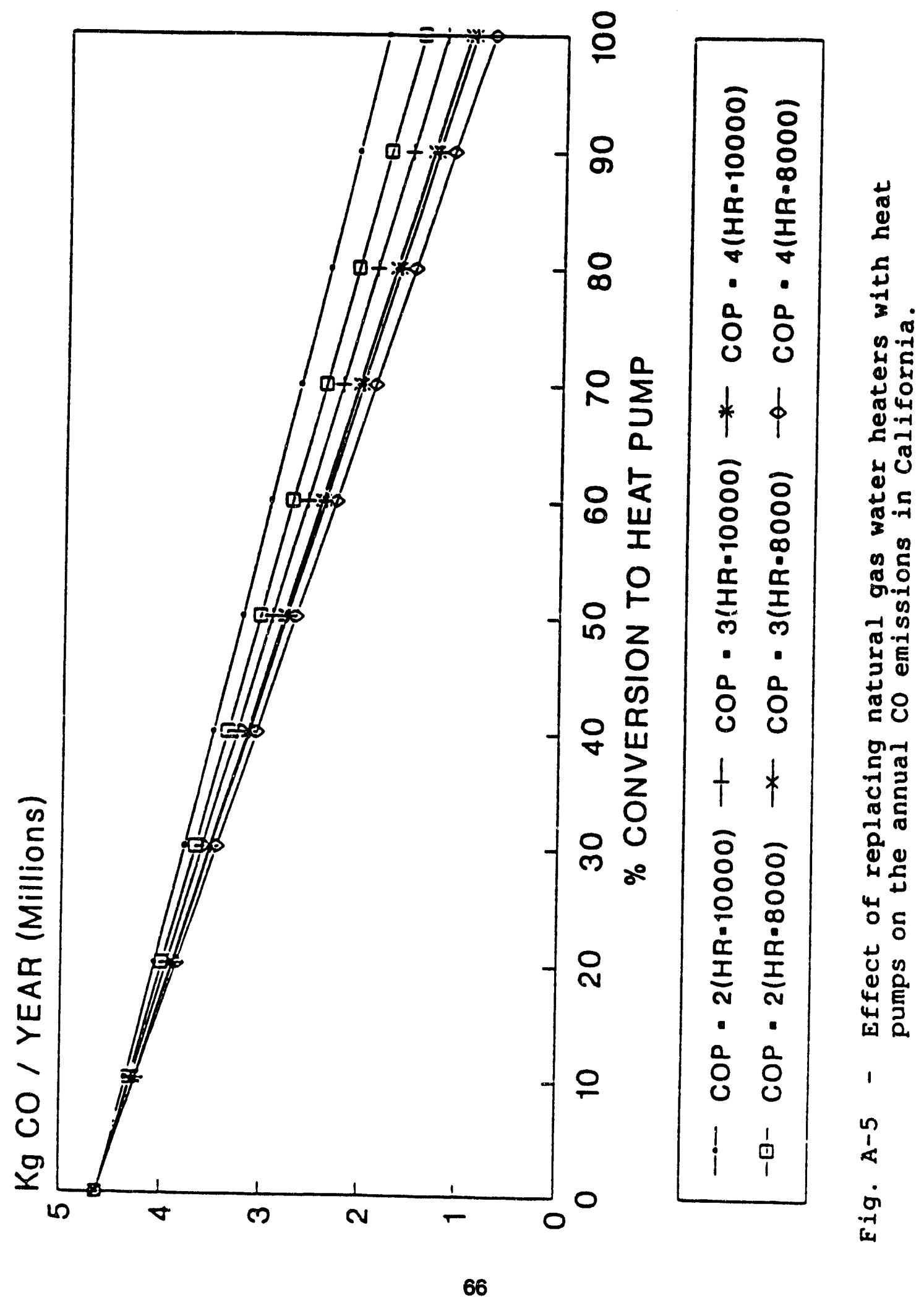




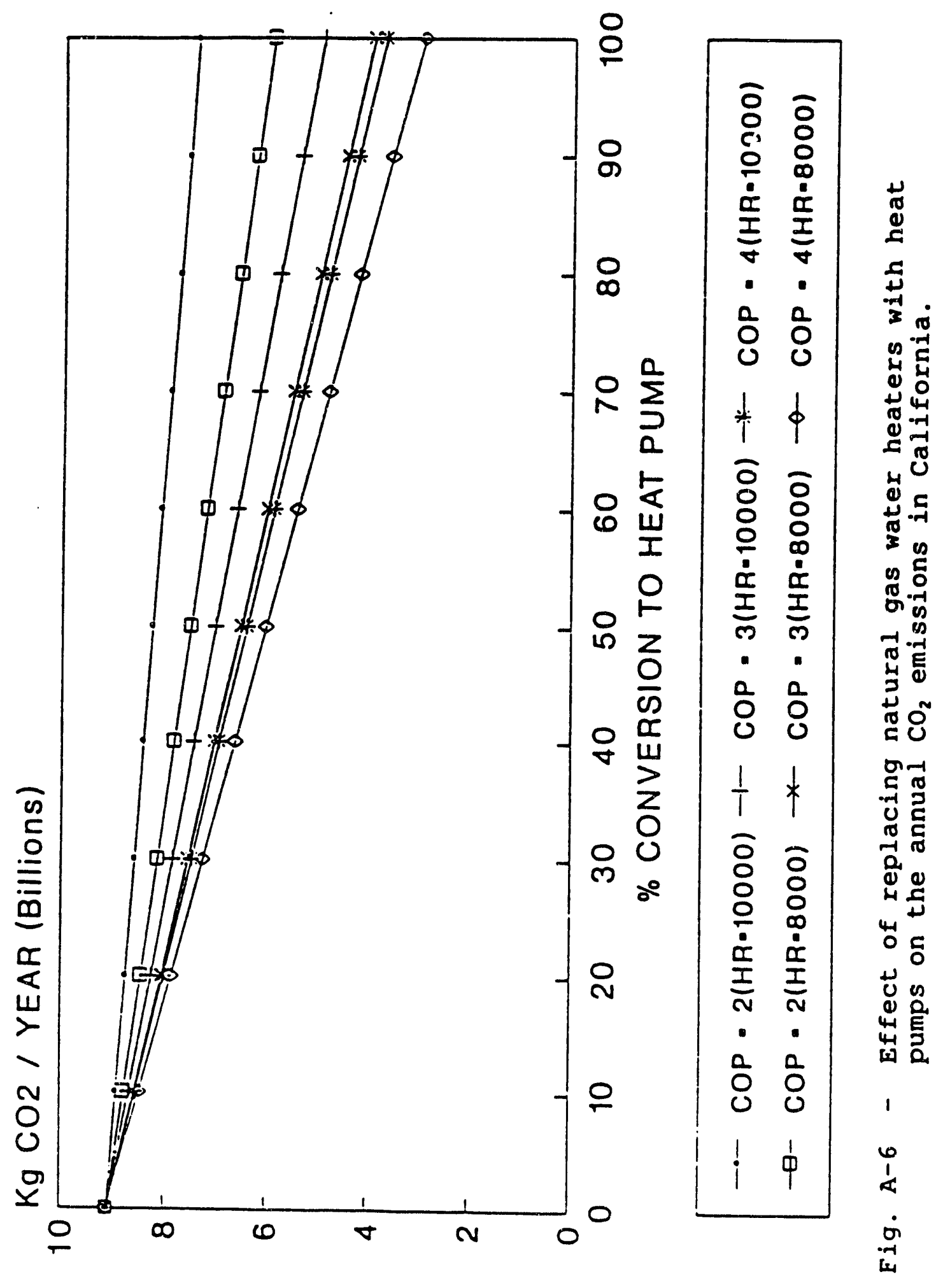




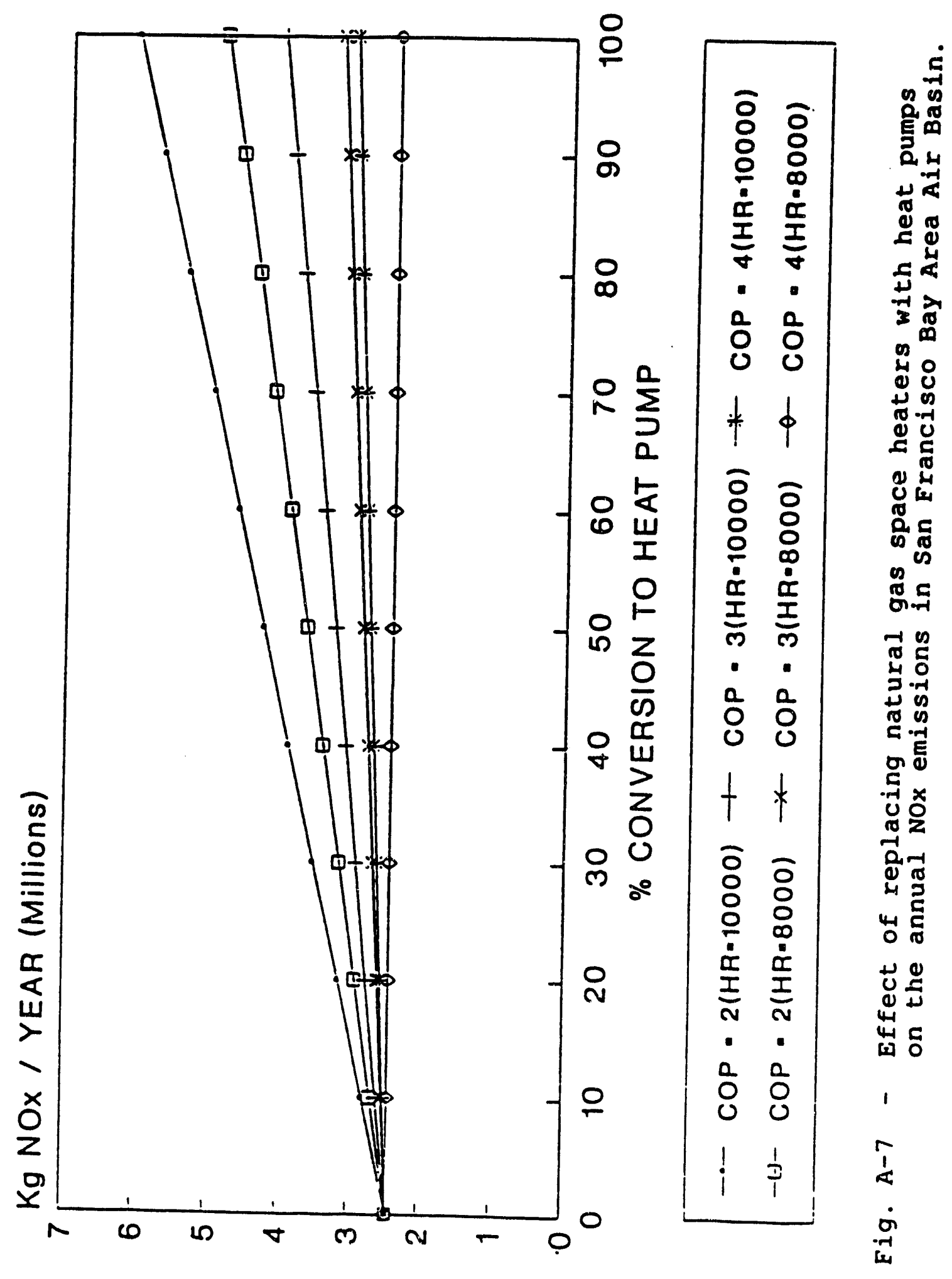




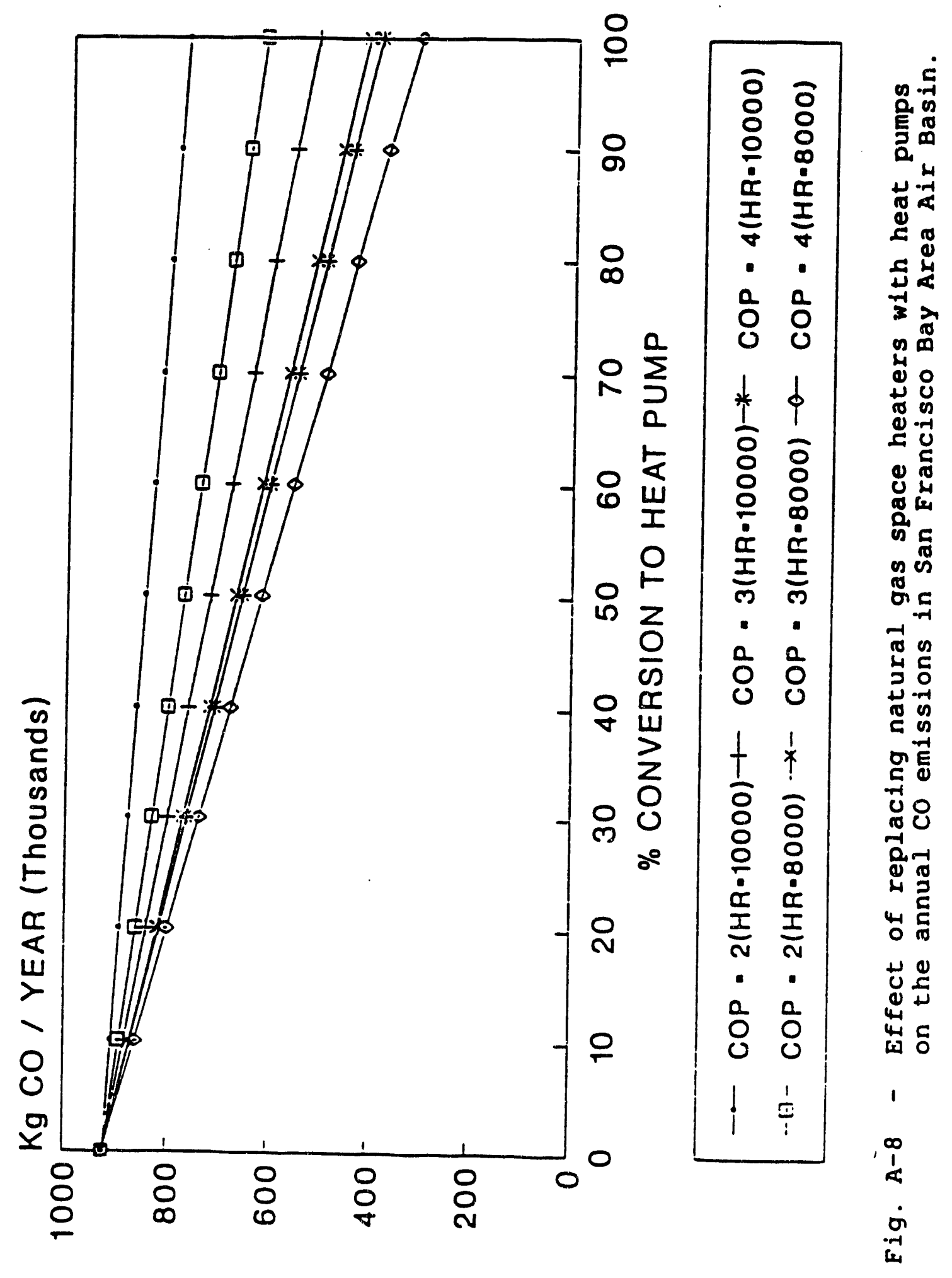




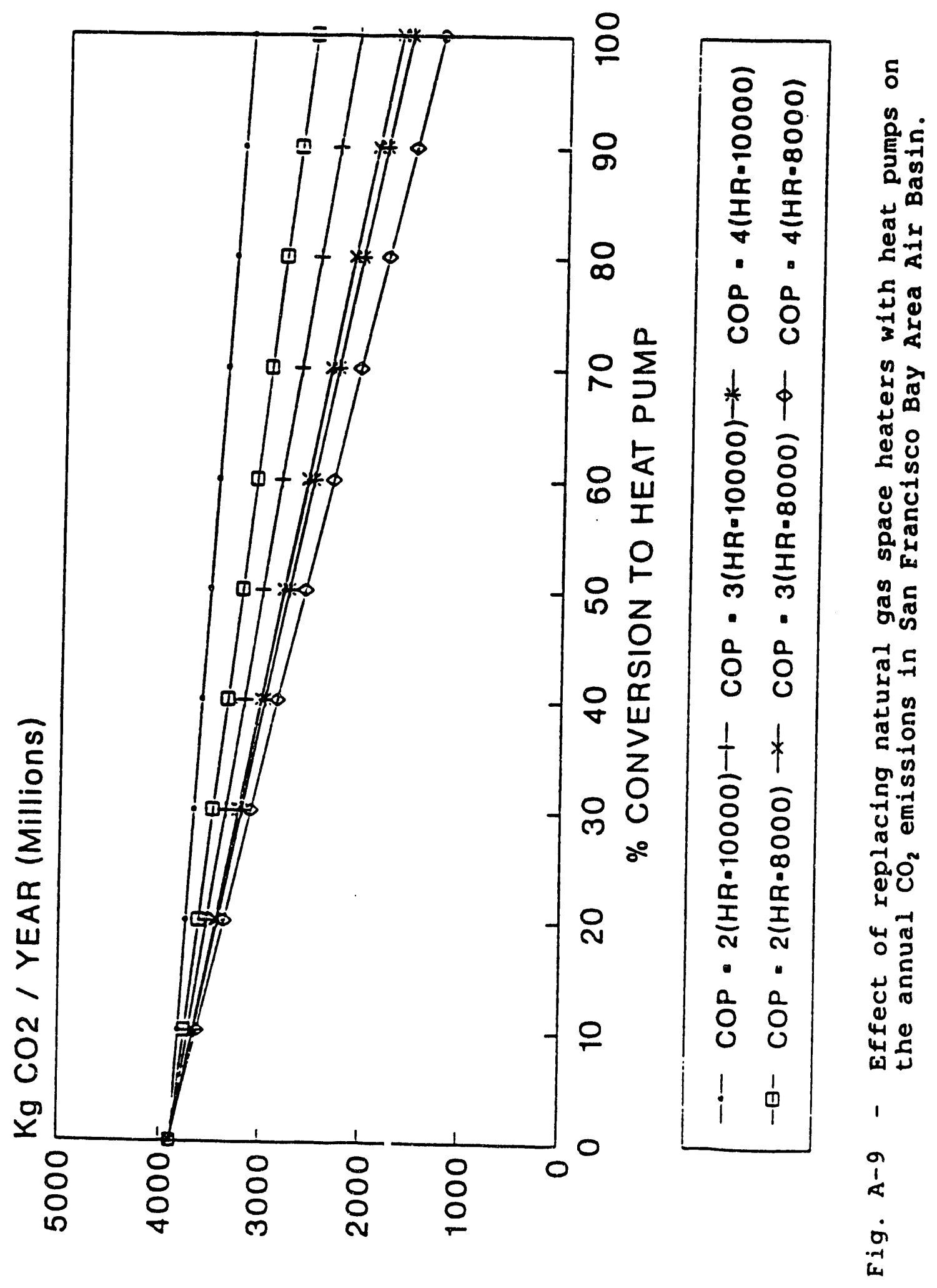




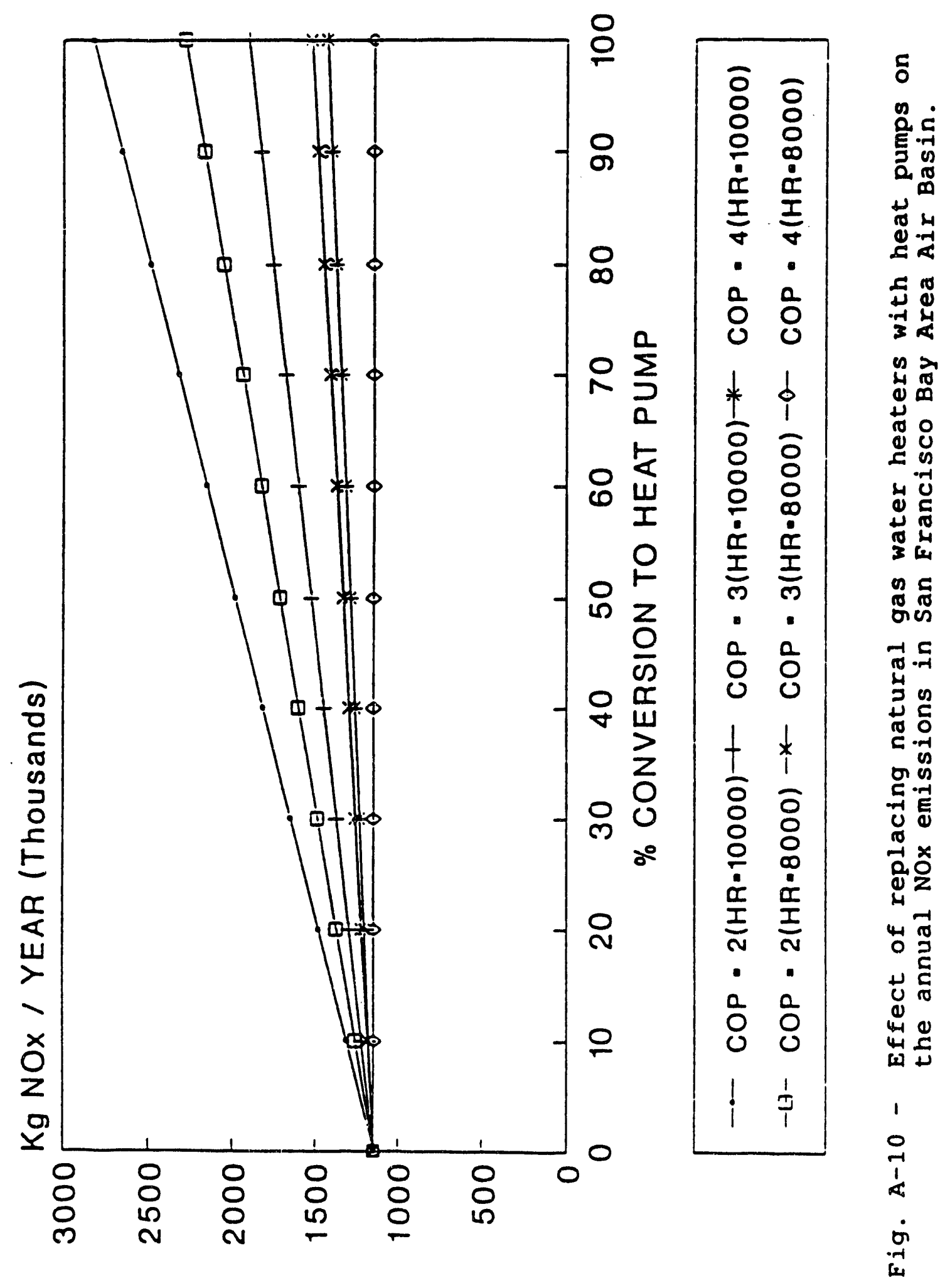




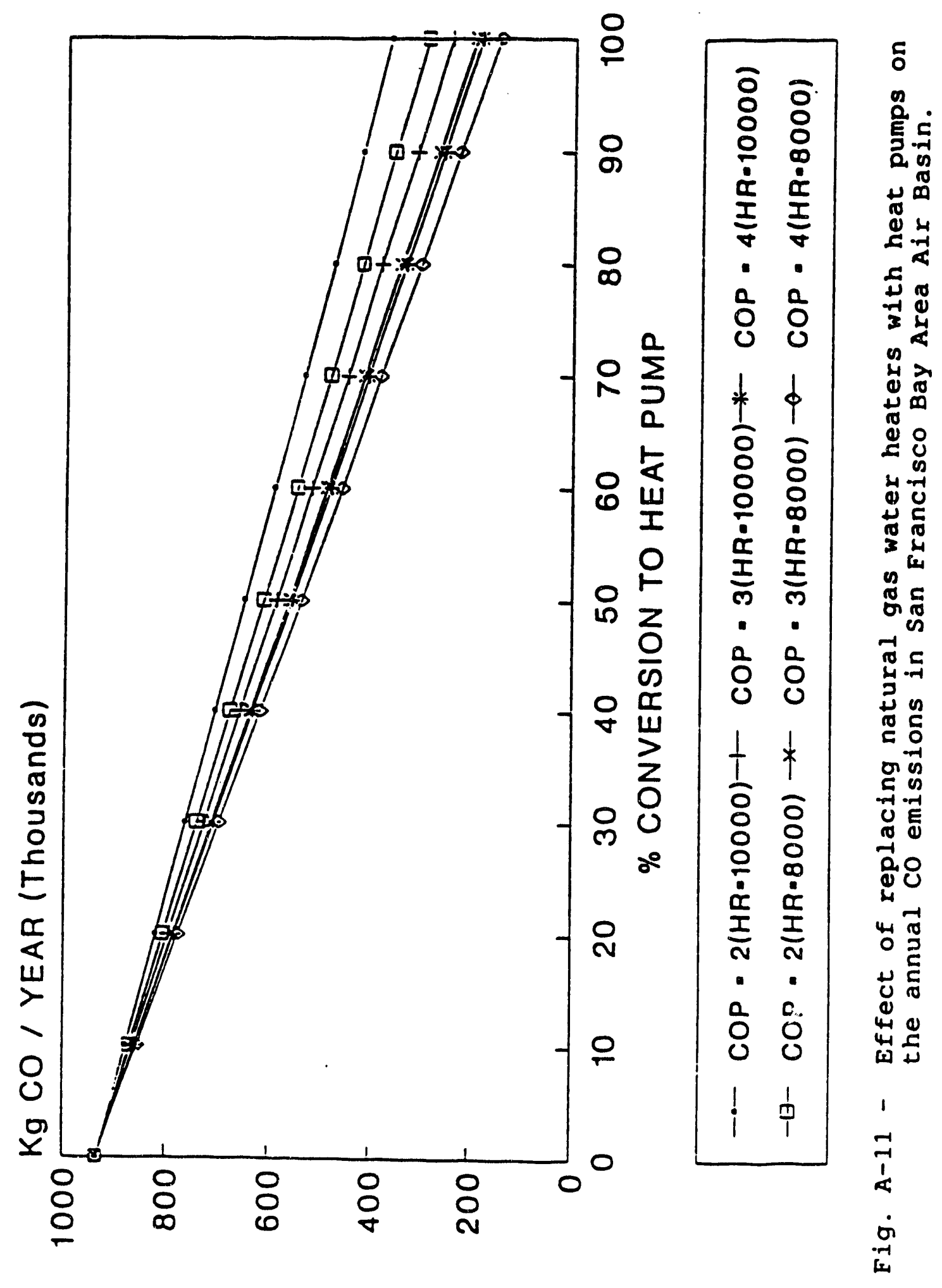




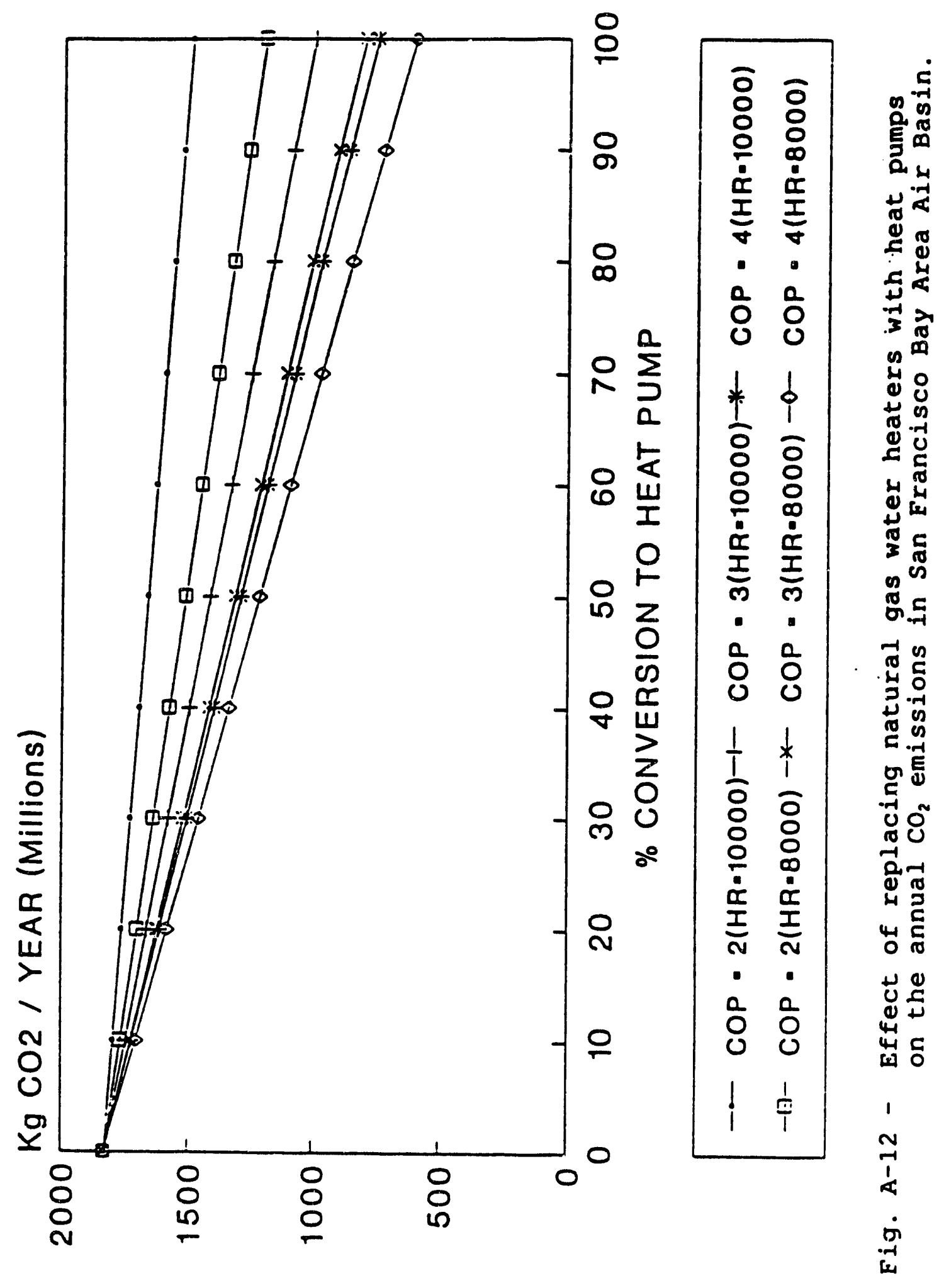




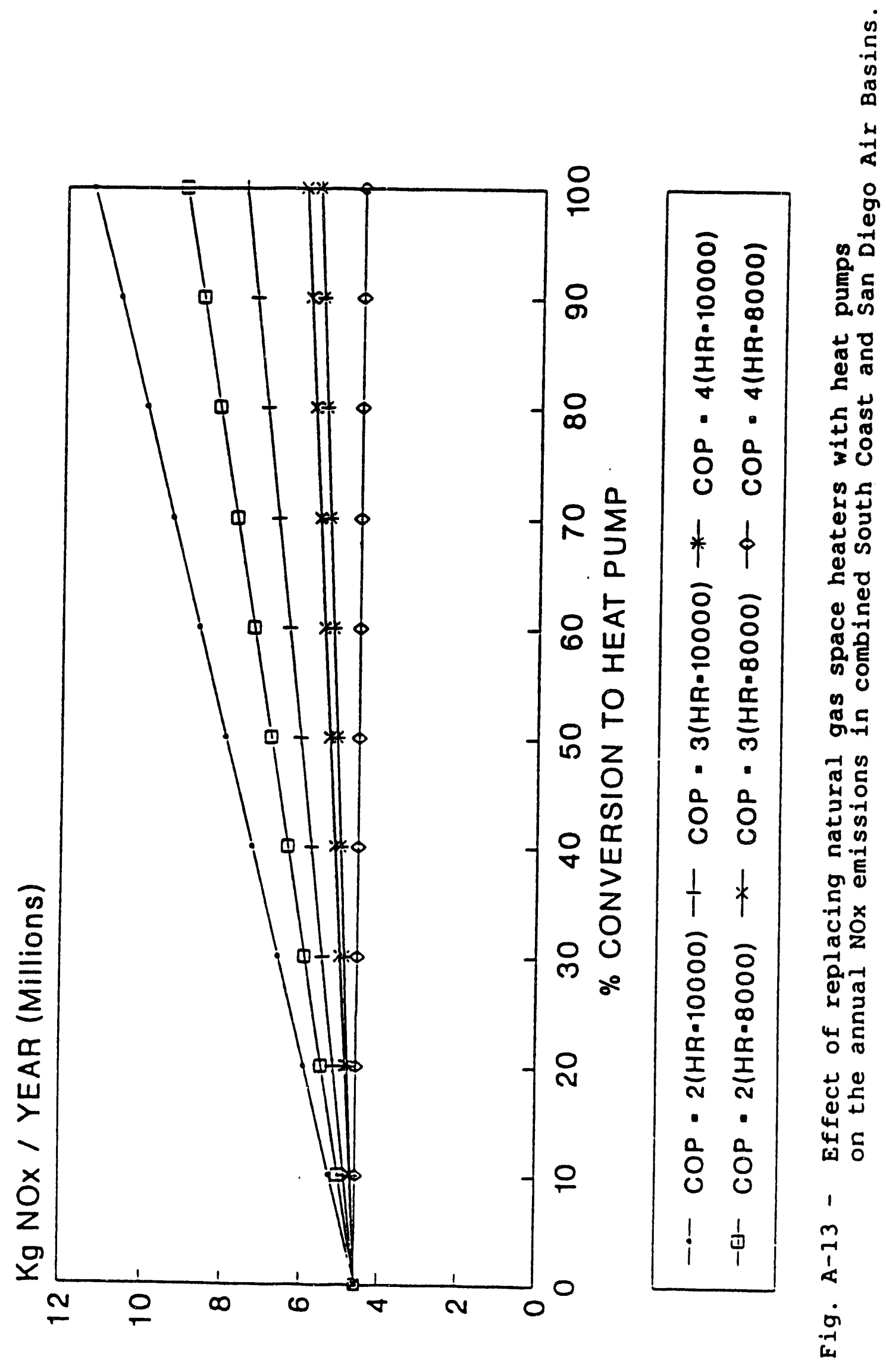




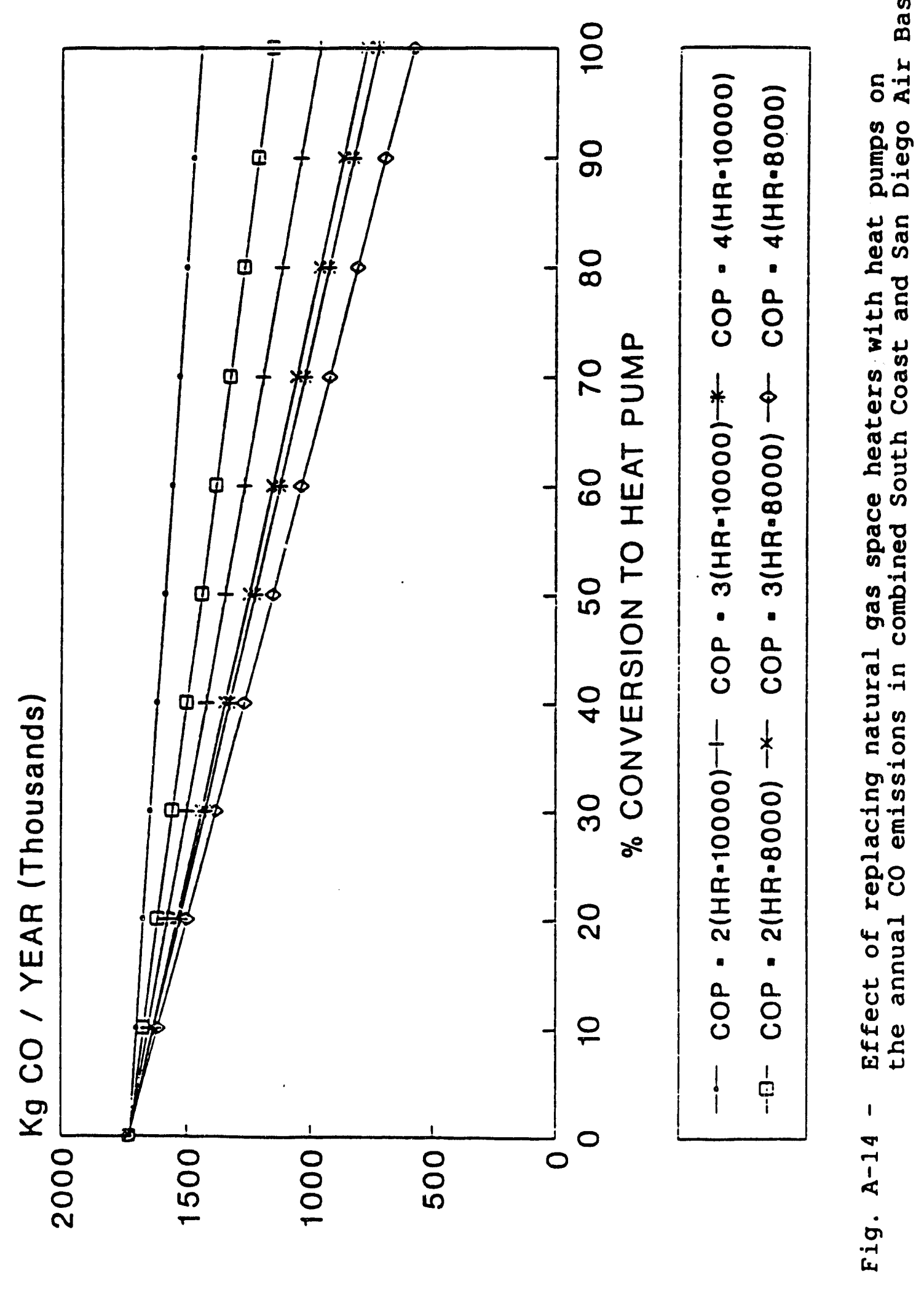




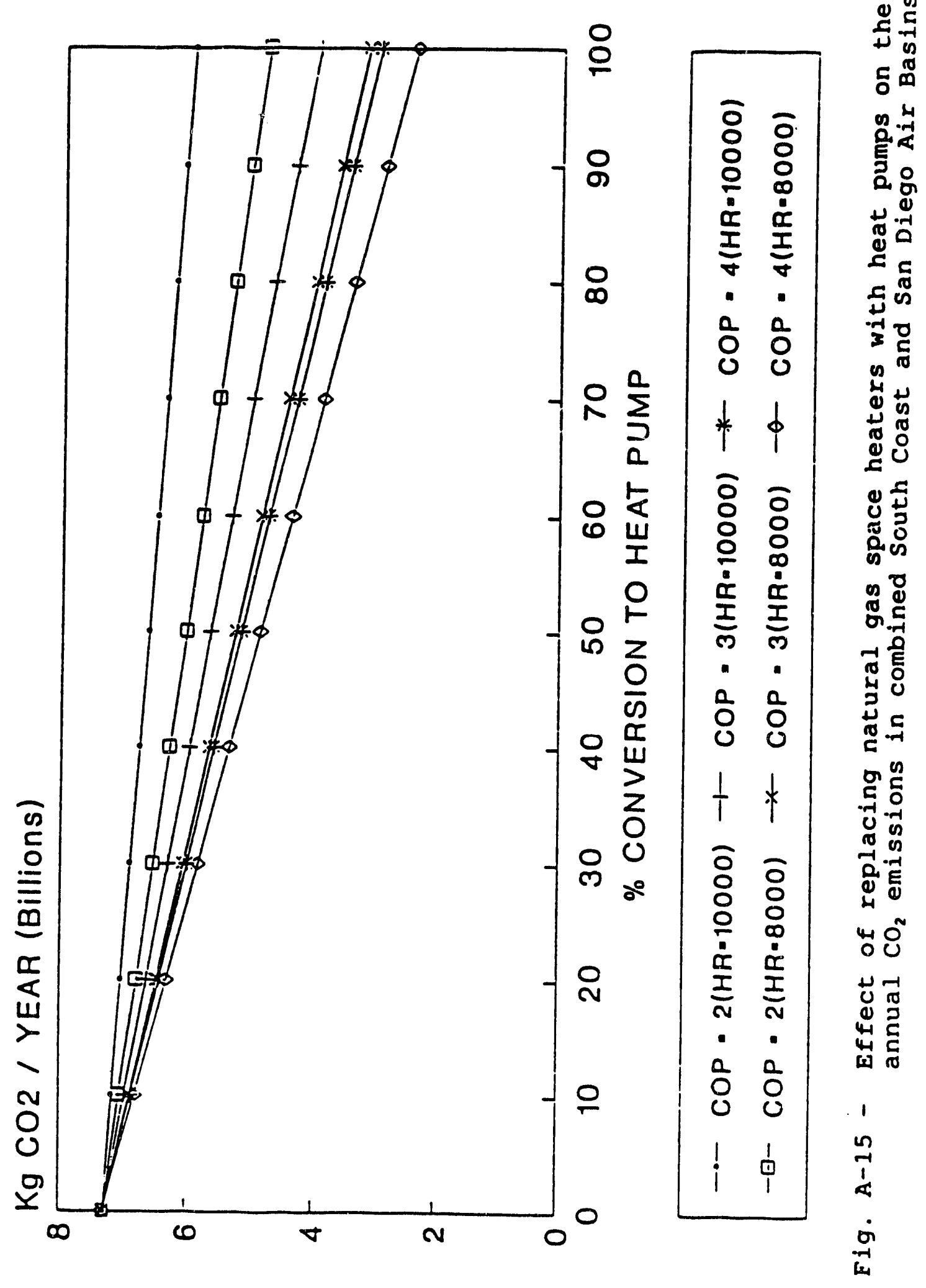




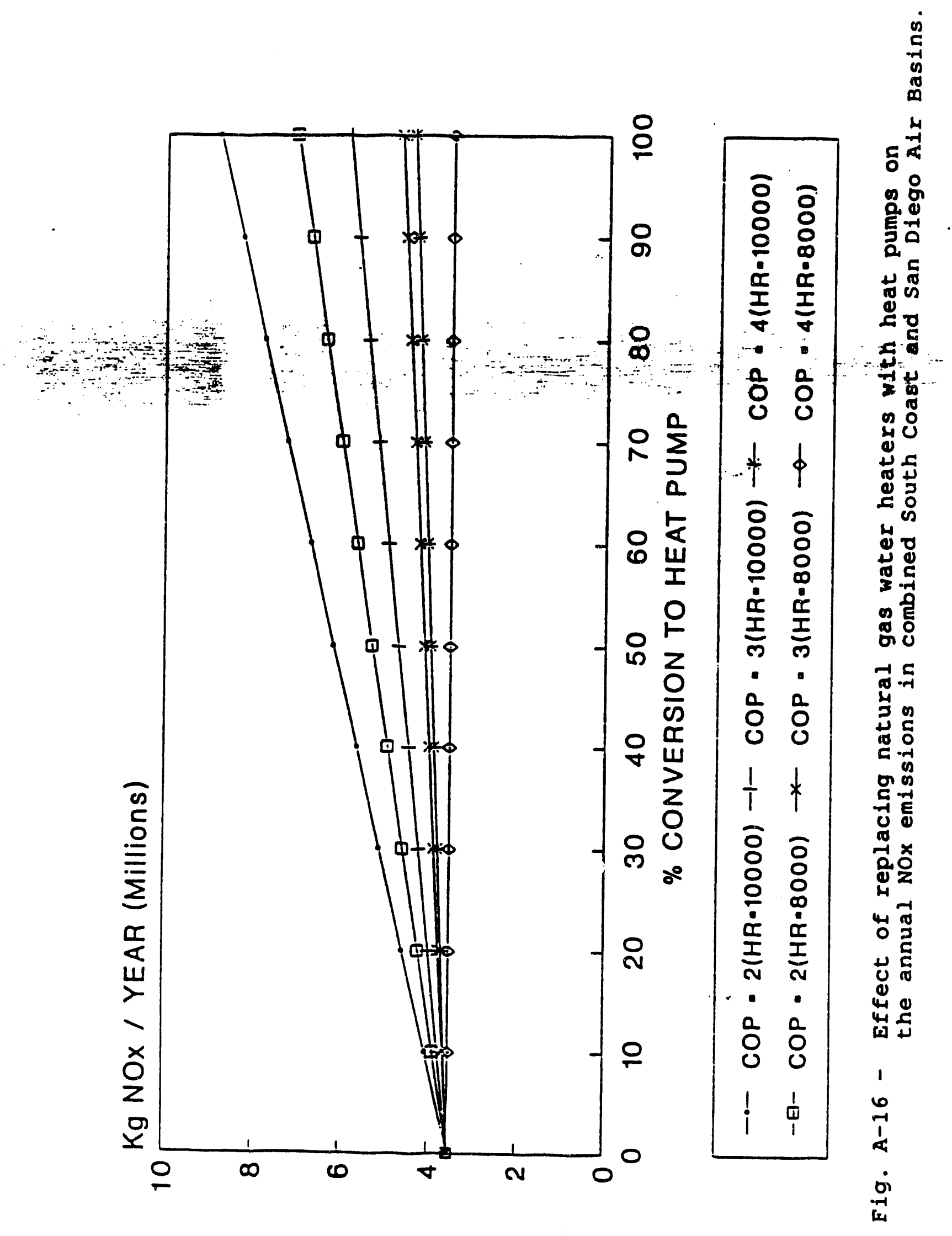




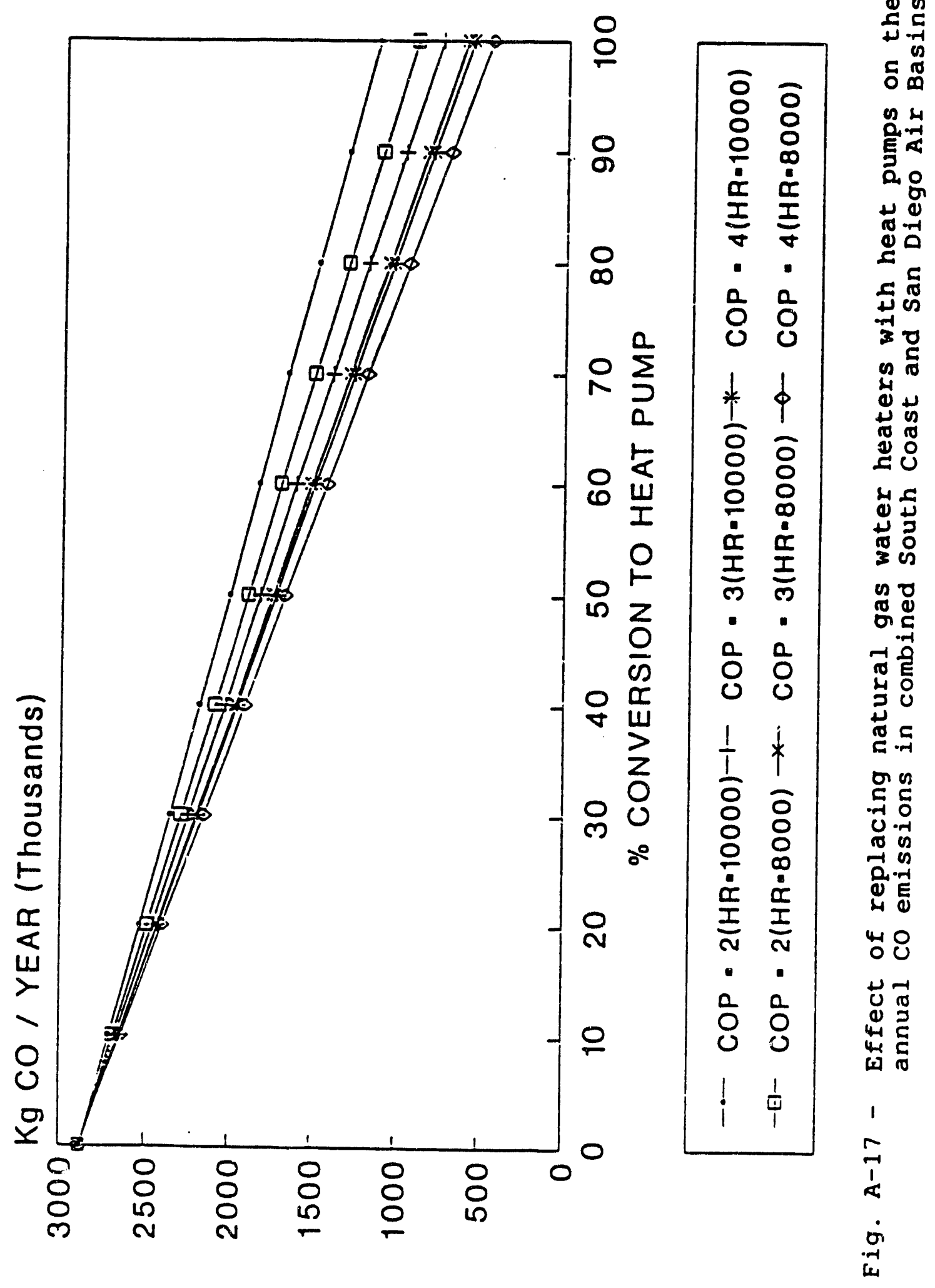




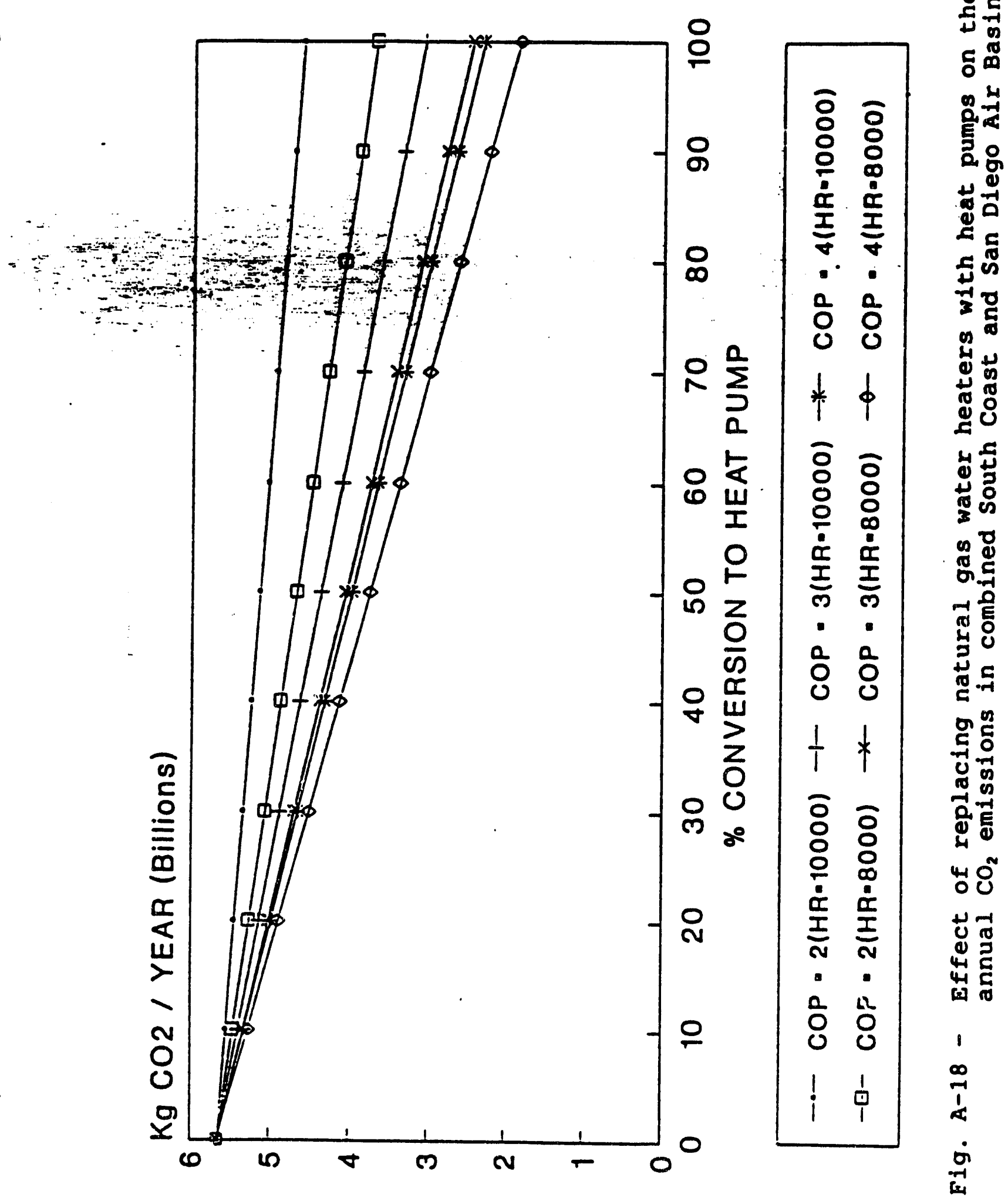



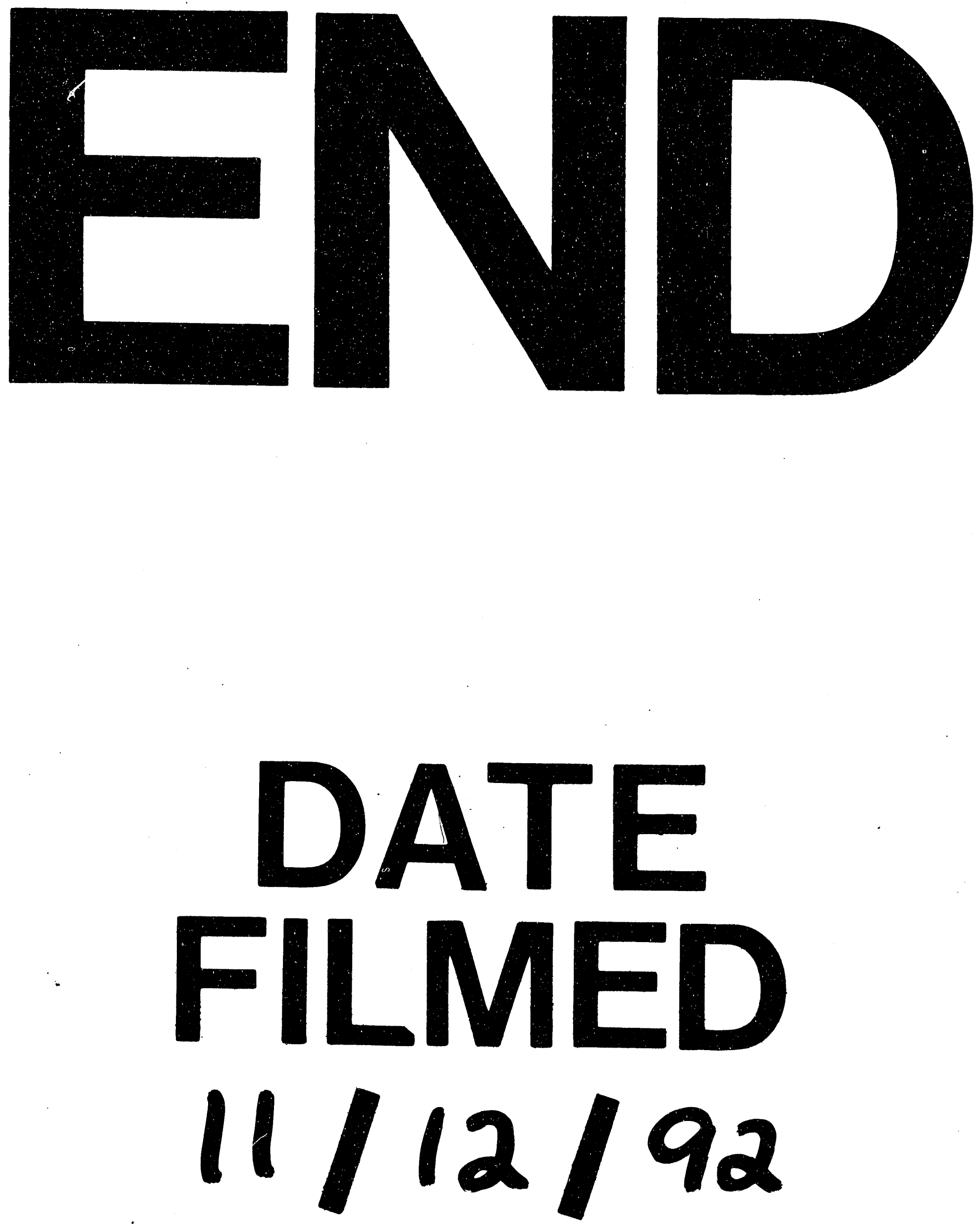
